\title{
Shedding Light on the Protonation States and Location of Protonated N Atoms of Adenine in Metal-Organic Frameworks
}

\author{
Andrzej Gladysiak, ${ }^{\dagger}$ Tu N. Nguyen, ${ }^{\dagger}$ Samantha L. Anderson, ${ }^{\dagger}$ Peter G. Boyd, ${ }^{\dagger}$ (๑) Robert G. Palgrave, ${ }^{\ddagger}$ \\ John Bacsa, ${ }^{\S}$ Berend Smit, ${ }^{\dagger}$ Matthew J. Rosseinsky, ${ }^{\| \odot}$ and Kyriakos C. Stylianou* ${ }^{*}{ }^{\dagger}$ \\ ${ }^{\dagger}$ Laboratory of Molecular Simulation (LSMO), Institut des Sciences et Ingénierie Chimiques (ISIC), École Polytechnique Fédérale de \\ Lausanne (EPFL Valais Wallis), Rue de l'Industrie 17, CH-1951 Sion, Switzerland \\ "University College London, Department of Chemistry, 20 Gordon St., London WC1H 0AJ, U.K. \\ ${ }^{\S}$ Department of Chemistry, Emory University, Atlanta, Georgia 30322, United States \\ "Department of Chemistry, University of Liverpool, Crown Street, Liverpool, L69 7ZD, U.K.
}

\section{Supporting Information}

ABSTRACT: We report the syntheses and structures of five metal-organic frameworks (MOFs) based on transition metals $\left(\mathrm{Ni}^{\mathrm{II}}, \mathrm{Cu}^{\mathrm{II}}\right.$, and $\left.\mathrm{Zn}^{\mathrm{II}}\right)$, adenine, and di-, tri-, and tetracarboxylate ligands. Adenine, with multiple $\mathrm{N}$ donor sites, was found to coordinate to the metal centers in different binding modes including bidentate (through N7 and N9, or N3 and N9) and tridentate (through N3, N7, and N9). Systematic investigations of the protonation states of adenine in each MOF structure via X-ray photoelectron spectroscopy revealed that adenine can
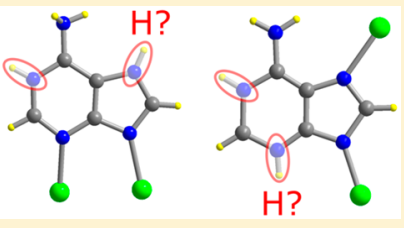
be selectively protonated through $\mathrm{N} 1, \mathrm{~N} 3$, or N7. The positions of $\mathrm{H}$ atoms connected to the $\mathrm{N}$ atoms were found from the electron density maps, and further supported by the study of $\mathrm{C}-\mathrm{N}-\mathrm{C}$ bond angles compared to the literature reports. DFT calculations were performed to geometrically optimize and energetically assess the structures simulated with different protonation modes. The present study highlights the rich coordination chemistry of adenine and provides a method for the determination of its protonation states and the location of protonated $\mathrm{N}$ atoms of adenine within MOFs, a task that would be challenging in complicated adenine-based MOF structures.

\section{INTRODUCTION}

Metal-organic frameworks (MOFs) are crystalline materials consisting of an infinite network of metal ions or clusters bridged by organic ligands through coordination bonds into one-, two-, or three-dimensional extended structures. ${ }^{1,2}$ Highly porous MOFs with various topologies, compositions, and properties have been reported, including MOF materials with high internal surface areas ${ }^{3}$ and void volumes, ${ }^{4}$ and remarkable low densities. ${ }^{5}$ MOFs can display permanent porosity and have been investigated for $\mathrm{CO}_{2}$ capture, ${ }^{6}$ and for the storage of strategically important gases such as $\mathrm{H}_{2}$ and $\mathrm{CH}_{4}{ }^{7,8}$ with the former being considered as an ideal energy carrier, while the latter has been suggested as a bridge fuel to a cleaner energy future. ${ }^{9,10}$ Multifunctional MOFs can be accessed by the careful selection of the components of the MOF, i.e., the organic ligands, the metal ions, and the encapsulated guest molecules, with applications in areas such as magnetism, ${ }^{11}$ sensing, ${ }^{12}$ gas separation, ${ }^{13}$ and catalysis ${ }^{14}$ being well noticed.

Among the organic ligands used for the synthesis of MOFs, nucleobases present an attractive family of ligands that can be incorporated within the MOF structures. ${ }^{15}$ This is due to their rigid structure and the large number of oxygen and nitrogen donor sites of different basicity; they are all readily available for metal coordination. In addition, nucleobases have the potential to form numerous complementary noncovalent interactions, including hydrogen bonds and $\pi-\pi$ stacking, which can further be exploited in order to prepare stable MOFs, of which the components are held together by not only coordination bonds but also the cumulative effect of numerous supramolecular interactions. ${ }^{16,17}$ Canonical nucleobases are often classified into two subgroups based on their structures: purines (adenine and guanine) and pyrimidines (cytosine, thymine, and uracil). With the higher number of heteroatoms, the purine nucleobases are the better bridging ligands than the pyrimidine nucleobases, especially with adenine being extensively used for forming complexes and networks with transition metals. ${ }^{18,19}$

Adenine (9HAde, Figure 1) is a rigid ligand with five potential coordination sites for metal binding, i.e., two imidazolate, two pyrimidinate $\mathrm{N}$ atoms, and an $-\mathrm{NH}_{2}$ group. The basicity order of the $\mathrm{N}$ atoms is $\mathrm{N} 9>\mathrm{N} 1>\mathrm{N} 7>\mathrm{N} 3>$ $\mathrm{N}_{10}{ }^{20}$ and the $\mathrm{p} K_{\mathrm{a}}$ of 9HAde is 9.8. Due to the 9HAde's imidazolate functionality with the coordination bridging mode of $\mu_{2}$-N7,N9, several MOFs with zeolitic topologies have been reported. ${ }^{21}$ However, due to the high versatility of adenine, which displays a variety of monodentate and bridging bidentate or tridentate metal coordination modes, an accurate prediction of Ade-based MOFs structures is often impossible. This, in fact, has been the impetus for the discovery of a large number of both porous and nonporous Ade-based MOFs with diverse structures and topologies that have been reported in the literature over the past few years. ${ }^{22-36}$ These MOFs have been

Received: November 3, 2017

Published: February 1, 2018 


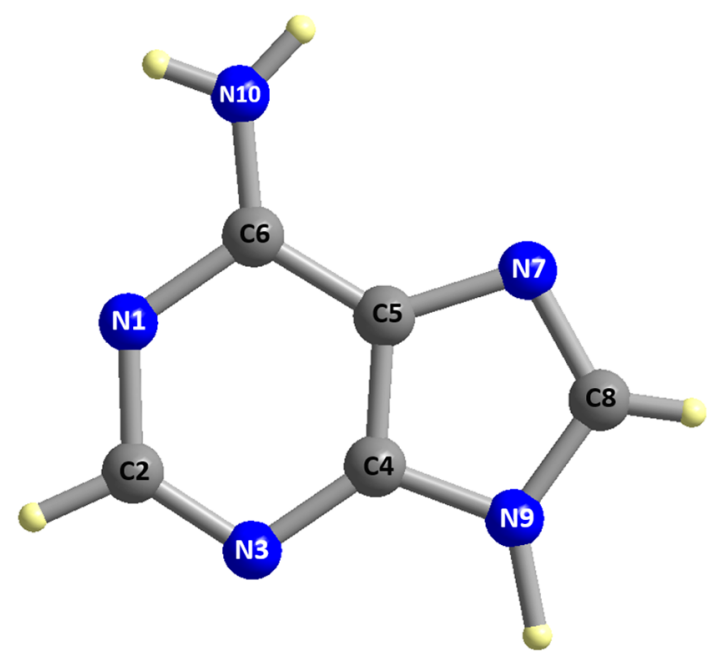

Figure 1. Structure of adenine (9HAde) protonated via N9. Color scheme: gray, $\mathrm{C}$; blue, $\mathrm{N}$; and yellow, $\mathrm{H}$.

shown to exhibit reversible hydrochromic behavior, ${ }^{36} \mathrm{CO}_{2} /$ $\mathrm{CH}_{4}$ selectivity, ${ }^{28}$ tunable porosity, ${ }^{29,31,35}$ and properties such as mesoporosity with low densities, high surface areas, and large pore volumes. ${ }^{32}$ Application in controlled drug delivery has also been explored. $^{26}$

Despite the high utility of adenine in MOF synthesis and due to the different possible protonation states of adenine $\left(\mathrm{H}_{2} \mathrm{Ade}^{+}\right.$, HAde, and $\mathrm{Ade}^{-}$), assigning the protonated $\mathrm{N}$ atoms and balancing the charge in crystal structures of many Ade-based MOFs is challenging, especially in complicated scaffolds. Exacting this information is vital to understand several properties of these materials, including acidity/basicity, catalytic cycles, and proton conductivity. The positions of $\mathrm{H}$ atoms are difficult to derive from X-ray diffraction data as $\mathrm{H}$ has the weakest X-ray scattering power among all elements. Neutron diffraction is more reliable in this context, although this technique requires special sample preparation methods and experimental instrumentation, which are not readily available in laboratories. Nevertheless, a rule of thumb for finding the location of protonated $\mathrm{N}$ atoms in heterocyclic compounds was postulated by Singh, stating that, for six-membered rings, the $\mathrm{C}-\mathrm{N}-\mathrm{C}$ angle should fall in the range of $125 \pm 3^{\circ}$ for the protonated $\mathrm{N}$ atoms, and $116 \pm 3^{\circ}$ when the $\mathrm{H}$ atom is absent. ${ }^{37}$ Since the rule is mainly valid for noncoordinated heterocyclic compounds, its use in Ade-based MOFs is not straightforward. In the present work, we combined X-ray photoelectron spectroscopy (XPS) with the study of the C$\mathrm{N}-\mathrm{C}$ angles derived from single-crystal X-ray diffraction (SCXRD) measurements, to determine the protonation states and to localize the protonated $\mathrm{N}$ atoms of adenine in five Adebased MOFs, which we referred to as SION-31, SION-32, SION-33, SION-34, and SION-35. These materials are based on the transition metals $\mathrm{Ni}^{\mathrm{II}}, \mathrm{Cu}^{\mathrm{II}}$, or $\mathrm{Zn}^{\mathrm{II}}$, adenine, and di-, tri-, and tetra-carboxylate ligands. The different binding modes of adenine ligands within these materials will be discussed based on their crystal structures, whereas their protonation states and the location of the protonated $\mathrm{N}$ atoms are reviewed through a detailed analysis of the XPS data and $\mathrm{C}-\mathrm{N}-\mathrm{C}$ angles.

\section{EXPERIMENTAL SECTION}

Synthesis. The reagents, including adenine (9HAde), 1,3,5benzenetricarboxylic acid $\left(\mathrm{H}_{3}\right.$ btc $)$, isophthalic acid $\left(\mathrm{H}_{2}\right.$ ipa $)$, 3,5pyrazoledicarboxylic acid $\left(\mathrm{H}_{3} \mathrm{pzdc}\right), 1,2,4,5$-benzenetetracarboxylic acid $\left(\mathrm{H}_{4}\right.$ btec $), \mathrm{NiCO}_{3}, \mathrm{CuCO}_{3}$, and $\mathrm{ZnCO}_{3}$, were purchased from Sigma-Aldrich and used as received.

Synthesis of $\left[\mathrm{Ni}_{2}\right.$ (btc) (Ade) $\left.\left(\mathrm{H}_{2} \mathrm{O}\right)_{5}\right] \cdot 3 \mathrm{H}_{2} \mathrm{O}$ (SION-31). A mixture of $\mathrm{NiCO}_{3}(71 \mathrm{mg}, 0.6 \mathrm{mmol}), \mathrm{H}_{3}$ btc $(63 \mathrm{mg}, 0.30 \mathrm{mmol})$, 9HAde (40 $\mathrm{mg}, 0.30 \mathrm{mmol})$, and water $(8 \mathrm{~mL})$ was placed in a Teflon reactor. The mixture was heated at $160{ }^{\circ} \mathrm{C}$ for 4 days, and then gradually cooled to room temperature at a rate of $0.1{ }^{\circ} \mathrm{C} / \mathrm{min}$. Green plate type crystals of SION-31 were obtained in $43 \%$ yield (based on $\mathrm{NiCO}_{3}$ ). Anal. Calcd for $\left(\left[\mathrm{Ni}_{2}\left(\mathrm{C}_{9} \mathrm{H}_{3} \mathrm{O}_{6}\right)\left(\mathrm{C}_{5} \mathrm{H}_{4} \mathrm{~N}_{5}\right)\left(\mathrm{H}_{2} \mathrm{O}\right)_{5}\right] \cdot\left(\mathrm{H}_{2} \mathrm{O}\right)_{3}\right): \mathrm{C} 28.12, \mathrm{H} 3.78, \mathrm{~N}$ 11.71; found: $\mathrm{C} 28.26, \mathrm{H} 3.68, \mathrm{~N} 12.00$.

Synthesis of [Ni(ipa)(3HAde)] (SION-32). The reaction conditions are similar to the ones described for SION-31, with the exception being that the molar ratio between $\mathrm{NiCO}_{3}: \mathrm{H}_{2}$ ipa:9HAde is $3: 2: 3(0.6$ mmol $\mathrm{NiCO}_{3}$ ). Green block-shaped crystals of SION-32 were obtained in $21 \%$ yield (based on $\mathrm{NiCO}_{3}$ ). Anal. Calcd for $\left(\left[\mathrm{Ni}\left(\mathrm{C}_{8} \mathrm{H}_{4} \mathrm{O}_{4}\right)\left(\mathrm{C}_{5} \mathrm{H}_{5} \mathrm{~N}_{5}\right)\right] \cdot\left(\mathrm{H}_{2} \mathrm{O}\right)_{0.2}\right):$ C 43.26, $\mathrm{H}$ 2.60, N 19.41; found: C 43.11, H 2.92, N 19.36 .

Synthesis of $\left.\left[\mathrm{Ni}_{2} \text { (btec) (7HAde) }\right)_{2}\left(\mathrm{H}_{2} \mathrm{O}\right)_{2}\right] \cdot 4 \mathrm{H}_{2} \mathrm{O}$ (SION-33). The reaction conditions are similar to the ones described for SION-31, with the exception being that the molar ratio between $\mathrm{NiC}$ $\mathrm{O}_{3}: \mathrm{H}_{4}$ btec:9HAde is $\left.2: 3: 3(0.6 \mathrm{mmol} \mathrm{NiCO})_{3}\right)$. Green block crystals of SION-33 were obtained in $38 \%$ yield (based on $\mathrm{NiCO}_{3}$ ). Anal. Calcd for $\left(\left[\mathrm{Ni}_{2}\left(\mathrm{C}_{10} \mathrm{H}_{2} \mathrm{O}_{8}\right)\left(\mathrm{C}_{5} \mathrm{H}_{5} \mathrm{~N}_{5}\right)_{2}\left(\mathrm{H}_{2} \mathrm{O}\right)_{2}\right] \cdot\left(\mathrm{H}_{2} \mathrm{O}\right)_{2.7}\right): \mathrm{C} 33.30, \mathrm{H}$ 2.96, N 19.42; found: $\mathrm{C} 33.38, \mathrm{H} 2.68, \mathrm{~N} 19.51$.

Synthesis of $\left[\mathrm{Cu}_{3}(\text { pzdc })_{2}(1 \mathrm{HAde})\left(\mathrm{H}_{2} \mathrm{O}\right)_{4}\right](\mathrm{SION}-34)$. A mixture of $\mathrm{CuCO}_{3} / \mathrm{H}_{3}$ pzdc/9HAde in a molar ratio of 1:1:1 $\left(0.40 \mathrm{mmol} \mathrm{CuCO}_{3}\right)$ in $3 \mathrm{~mL}$ of $\mathrm{H}_{2} \mathrm{O}$ was heated at $120^{\circ} \mathrm{C}$ for $36 \mathrm{~h}$. Blue block crystals of SION-34 were obtained in $35 \%$ yield (based on $\mathrm{CuCO}_{3}$ ). Anal. Calcd for $\left(\left[\mathrm{Cu}_{3}\left(\mathrm{C}_{5} \mathrm{HN}_{2} \mathrm{O}_{4}\right)_{2}\left(\mathrm{C}_{5} \mathrm{H}_{5} \mathrm{~N}_{5}\right)\left(\mathrm{H}_{2} \mathrm{O}\right)_{4}\right] \cdot\left(\mathrm{H}_{2} \mathrm{O}\right)_{0.3}\right)$ : C 25.44, $\mathrm{H} 2.20$, $\mathrm{N}$ 17.81; found: $\mathrm{C} 25.41, \mathrm{H} 2.33, \mathrm{~N} 17.90$.

Synthesis of $\left[\mathrm{Zn}_{2}(\right.$ btc $)\left(\right.$ Ade) $\left.\left(\mathrm{H}_{2} \mathrm{O}\right)_{2}\right]$ (SION-35). A mixture of $\mathrm{ZnCO}_{3}(47 \mathrm{mg}, 0.40 \mathrm{mmol}), \mathrm{H}_{3} \mathrm{btc}(84 \mathrm{mg}, 0.40 \mathrm{mmol}), 9 H A d e$ $(54 \mathrm{mg}, 0.40 \mathrm{mmol})$, and water $(6 \mathrm{~mL})$ was placed in a Teflon reactor. The mixture was heated at $150{ }^{\circ} \mathrm{C}$ for $72 \mathrm{~h}$, and then gradually cooled to room temperature at a rate of $0.3{ }^{\circ} \mathrm{C} / \mathrm{min}$. Colorless needle crystals of SION-35 were obtained in $22 \%$ yield (based on $\mathrm{ZnCO}_{3}$ ). Anal. Calcd for $\left(\left[\mathrm{Zn}_{2}\left(\mathrm{C}_{9} \mathrm{H}_{3} \mathrm{O}_{6}\right)\left(\mathrm{C}_{5} \mathrm{H}_{4} \mathrm{~N}_{5}\right)\left(\mathrm{H}_{2} \mathrm{O}\right)_{2}\right] \cdot\left(\mathrm{H}_{2} \mathrm{O}\right)_{0,7}\right)$ : C 32.45, H 3.39, N 13.52; found: $\mathrm{C} 32.68, \mathrm{H} 3.42, \mathrm{~N} 13.33$.

Single-Crystal X-ray Diffraction (SCXRD). SCXRD data of SION-31 were collected on a Bruker AXS SMART Apex diffractometer equipped with a CCD detector. The X-ray beam was generated using graphite monochromated Mo $\mathrm{K} \alpha$ radiation from a molybdenum X-ray tube operating at $40 \mathrm{kV}$ and $30 \mathrm{~mA}$. A single crystal was immersed in silicone oil, and picked with a polyimide loop which in turn was mounted on a goniometer. Diffraction data were collected at $100.0 \mathrm{~K}$. Single crystals of SION-32, SION-33, SION-34, and SION-35 were measured using the synchrotron radiation at the European Synchrotron Radiation Facility, Beamline BM01. Suitable single crystals were selected and mounted onto the diffractometer equipped with a CCD area detector. The crystals were kept at $100.0 \mathrm{~K}$ during data collection. Using Olex $2,{ }^{38}$ their structures were solved with the ShelXT structure solution program using Intrinsic Phasing ${ }^{39}$ and refined with the ShelXL refinement package using Least Squares minimization. ${ }^{40}$ Atomic positions were found from the differenceFourier maps and refined anisotropically for all non- $\mathrm{H}$ atoms. Positions of aromatic $\mathrm{H}$ atoms were refined using a riding model, while $\mathrm{H}$ atoms in methyl and hydroxy groups were refined as in idealized rotating groups. $U_{\text {iso }}$ for $\mathrm{H}$ atoms were set to 1.2 times $U_{\text {eq }}$ of neighboring atoms, and 1.5 times $U_{\mathrm{eq}}$ of atoms in terminating groups.

Powder X-ray Diffraction (PXRD). PXRD data of SION-31, SION-32, SION-33, SION-34, and SION-35 were collected with Cu $\mathrm{K} \alpha$ radiation at $298 \mathrm{~K}$. Their phase purity was confirmed by the comparison of the simulated PXRD patterns (derived from the Mercury software) to the experimental ones.

X-ray Photoelectron Spectroscopy (XPS). XPS spectra of SION-31, SION-32, SION-33, SION-34, and SION-35 were recorded on a Scienta ESCA 300 spectrometer located at the NCESS facility at Daresbury Laboratory, U.K., which incorporated a rotating anode $\mathrm{Al} \mathrm{K} \alpha(h \nu=1486.6 \mathrm{eV}) \mathrm{X}$-ray source and had an effective instrument resolution of $400 \mathrm{meV}$. The spectrometer was 

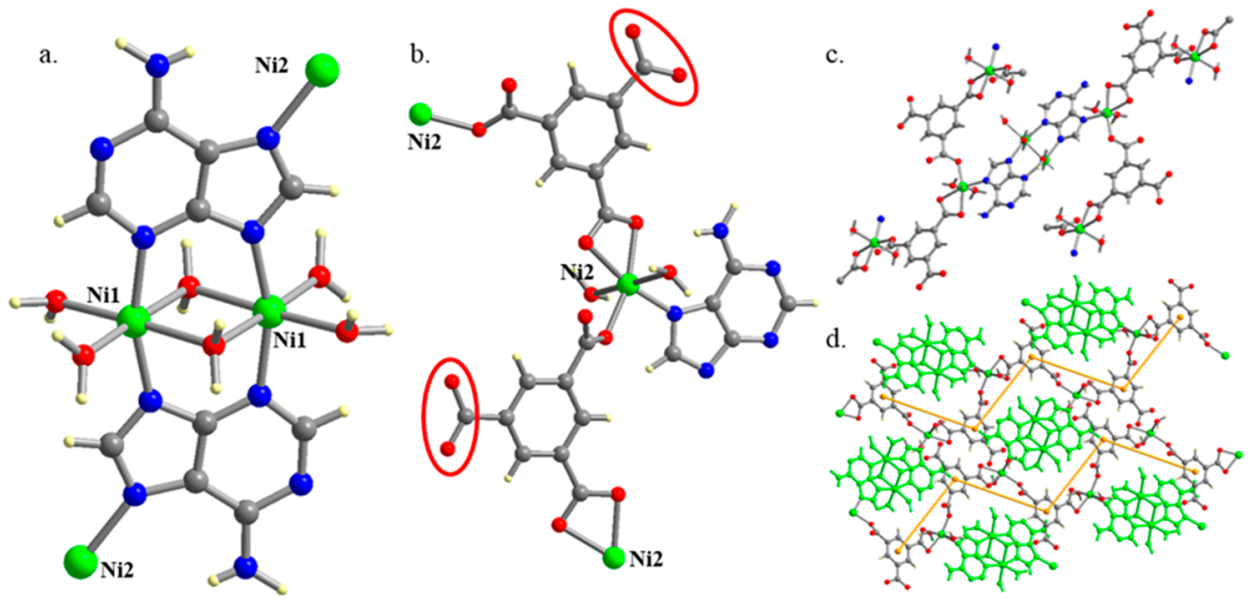

Figure 2. SION-31: (a) Depiction of the Ni-Ade secondary building unit (SBU) $\left[\mathrm{Ni}_{2}(\text { Ade })_{2}\left(\mathrm{H}_{2} \mathrm{O}\right)_{4}\left(\mu_{2}-\mathrm{H}_{2} \mathrm{O}\right)_{2}\right]^{2+}$, with Ade ${ }^{-}$acting as the bridging ligand via N3, N7, and N9, linking the Ni-Ade SBU with Ni2. (b) Coordination environment of Ni2; the carboxylate group of btc $\mathrm{c}^{3-}$ is not involved in coordination to $\mathrm{Ni}^{\mathrm{II}}$ and is enclosed in a red ellipse. (c) Mono- and bidentate coordination modes of the btc ${ }^{3-}$ ligand. (d) The Ni-Ade SBU (colored in green) connects the btc-based chains (orange zigzag line), resulting in a two-dimensional layered structure. Color scheme: $\mathrm{Ni}$, green; $\mathrm{C}$, gray; $\mathrm{O}$, red; $\mathrm{N}$, blue; and $\mathrm{H}$, yellow.

calibrated regularly to set the Fermi edge of a silver reference sample at zero binding energy. Sample charging was compensated for using an electron flood gun. The binding energy scale was referenced using the adventitious carbon $\mathrm{C}$ 1s peak which was set to $284.6 \mathrm{eV}$. Powder samples were prepared by pressing into indium foil, with care taken to ensure that no In signal was observed in the resulting spectra.

Other Characterizations. Thermogravimetric analyses (TGA) for SION-31, SION-32, SION-33, SION-34, and SION-35 were performed under an air atmosphere using a thermogravimetric instrument SDT Q600. The heating rate was set to $5{ }^{\circ} \mathrm{C} / \mathrm{min}$ until $600{ }^{\circ} \mathrm{C}$, and then the samples were cooled to room temperature at a rate of $10{ }^{\circ} \mathrm{C} / \mathrm{min}$. Elemental analysis results $(\mathrm{C}, \mathrm{H}$, and $\mathrm{N})$ were obtained using a Thermo EA1112 Flash CHNS-O Analyzer.

Density Functional Theory (DFT) Calculations. The GPUenabled ${ }^{41,42}$ Vienna Ab initio Simulation Package (VASP) v. 5.4.4 $4^{43-46}$ was used for all electronic structure calculations using the PBE exchange/correlation functional with the D3 dispersion correction of Grimme. ${ }^{47,48}$ The PBE+D3 functional was chosen due to its performance for geometry optimization in a test set of diverse MOF materials, compared with several commonly used exchange/correlation functionals. ${ }^{49}$ Similar results were obtained with different functionals (see Table S1 of the Supporting Information). All calculations were spin unrestricted. The Ni(II) ions in SION-32 and SION-33 were treated in their high spin electronic states. Each structure was relaxed to their minimum energy state using a conjugate gradient algorithm on both the ions and the cell shape. The forces were considered converged when the maximum force on the ions was below a $0.02 \mathrm{eV} /$ $\AA$ threshold. A plane-wave cutoff of $1000 \mathrm{eV}$ was used for energy calculations, and a PAW pseudopotential was used. ${ }^{50} \mathrm{~A} \Gamma$-centered $k$ point mesh was used. At each ionic step, the ground-state electronic configuration was obtained using the residual minimization method direct inversion of the iterative subspace (RMM-DIIS) algorithm and considered converged when the change in energy was below $10^{-5} \mathrm{eV}$.

\section{RESULTS AND DISCUSSION}

Synthesis and Characterization. The syntheses of SION31, SION-32, SION-33, SION-34, and SION-35 were all performed under hydrothermal reaction conditions, with the reactants being carbonate metal salts, adenine, and different carboxylate ligands in pure water. The molar ratios of the reactants were screened to obtain phase-pure products.

Green block type crystals of SION-31 were formed as a pure phase, with the formula of $\left[\mathrm{Ni}_{2}(\mathrm{btc})(\right.$ Ade $\left.)\left(\mu_{2}-\mathrm{H}_{2} \mathrm{O}\right)\left(\mathrm{H}_{2} \mathrm{O}\right)_{4}\right]$. $3 \mathrm{H}_{2} \mathrm{O}$ as determined by SCXRD (vide infra). This is well in agreement with the molar ratio of the reactants $\mathrm{NiC}$ $\mathrm{O}_{3}: \mathrm{H}_{3}$ btc:9HAde of 2:1:1 in the reaction. When $\mathrm{H}_{2} \mathrm{ipa}$, a dicarboxylic acid, is used instead of $\mathrm{H}_{3}$ btc, SION-32 was formed, with the formula of [Ni(ipa)(3HAde)]. It is worth noting that the use of a slight excess $\mathrm{NiCO}_{3}$ and 9 HAde (molar ratio of $\mathrm{NiCO}_{3}: \mathrm{H}_{2}$ ipa:9HAde of 3:2:3) is crucial to obtain the pure phase of SION-32. Similarly, in the case of SION-33, $\left[\mathrm{Ni}_{2}(\mathrm{btec})(7 \mathrm{HAde})_{2}\left(\mathrm{H}_{2} \mathrm{O}\right)_{2}\right] \cdot 4 \mathrm{H}_{2} \mathrm{O}$, the slight excess of the tetracarboxylic acid $\mathrm{H}_{4}$ btec and adenine (molar ratio of $\mathrm{NiCO}_{3}: \mathrm{H}_{4}$ btec:9HAde of 2:3:3) is the key for the formation of the product.

Since different MOF structures were obtained with different carboxylate ligands, the metal ion and/or the carboxylate ligands were changed to further explore the versatility of this reaction scheme. SION-34, $\left[\mathrm{Cu}_{3}(\mathrm{pzdc})_{2}(1 \mathrm{HAde})\left(\mathrm{H}_{2} \mathrm{O}\right)_{4}\right]$, formed when $\mathrm{CuCO}_{3}$ and $\mathrm{H}_{3}$ pzdc were used, while SION-35, $\left[\mathrm{Zn}_{2}(\mathrm{btc})(\right.$ Ade $\left.)\left(\mathrm{H}_{2} \mathrm{O}\right)_{2}\right]$, was the product when $\mathrm{ZnCO}_{3}$ was combined with $\mathrm{H}_{3}$ btc.

The bulk phase purity of SION-31, SION-32, SION-33, SION-34, and SION-35 was confirmed by PXRD, with both the theoretical and the experimental X-ray powder diffraction patterns well in agreement (Figure S1). Their purity was further confirmed through elemental analysis (see the Experimental Section) and SEM images (Figures S2-S4).

The thermal stability of SION-31, SION-32, SION-33, SION-34 and SION-35 was also investigated through TGA analysis. As illustrated in Figure S5, the TGA profiles of SION31, SION-32, SION-33, SION-34, and SION-35 follow the same trend, showing an initial weight loss corresponding to the removal of the lattice $\mathrm{H}_{2} \mathrm{O}$ molecules, followed by the release of the metal bound $\mathrm{H}_{2} \mathrm{O}$ molecules at higher temperature (Table S2). The weight loss in SION-31 occurred in two steps: i. the first step corresponds to the loss of the guest $\mathrm{H}_{2} \mathrm{O}$ molecules in the temperature range of $30-130{ }^{\circ} \mathrm{C}$; ii. the second step is attributed to the loss of the coordinated $\mathrm{H}_{2} \mathrm{O}$ molecules in the temperature range of $130-250{ }^{\circ} \mathrm{C}$. A total weight loss of $22.5 \%$ is in agreement with the loss calculated from elemental analysis (23.4\%). Decomposition of the framework starts at $400{ }^{\circ} \mathrm{C}$. SION-32 shows no weight loss as there are no bound $\mathrm{H}_{2} \mathrm{O}$ molecules to the metal center and the cavities are too small to accommodate any $\mathrm{H}_{2} \mathrm{O}$ molecules. This is consistent with the 

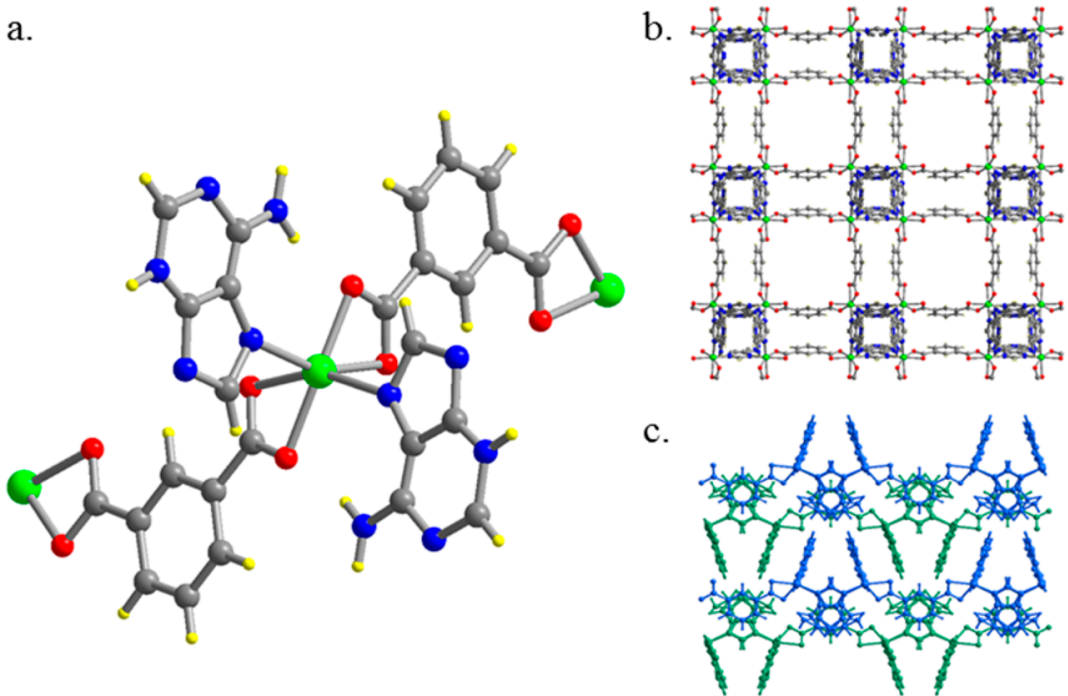

Figure 3. SION-32: (a) Illustration of the distorted octahedral coordination environment of $\mathrm{Ni}^{\mathrm{II}}$ in SION-32; each $\mathrm{Ni}^{\mathrm{II}}$ is coordinated by two ipa ${ }^{2-}$ and two 3HAde ligands. (b) The coordination of $\mathrm{ipa}^{2-}$ and 3HAde around $\mathrm{Ni}^{\mathrm{II}}$ affords a two-dimensional layered structure. (c) A single twodimensional sheet in SION-32 along a-axis, showing that the orientation of ipa ${ }^{2-}$ and 3HAde around the $\mathrm{Ni}^{\mathrm{II}}$ of the distorted octahedral coordination results in the generation of a close packed two-dimensional layer. Color scheme: Ni, green; C, gray; O, red; N, blue; and $\mathrm{H}$, yellow.

elemental analysis as it was found that there are $0.2 \mathrm{H}_{2} \mathrm{O}$ guest molecules per formula unit comprising $0.4 \%$ of the total weight of the structure. The TGA profile of SION-32 shows its excellent stability up to $450{ }^{\circ} \mathrm{C}$. The same trend with the profile for SION-31 was also observed for SION-33. The final weight loss of $14.4 \%$ is slightly larger than the one calculated from elemental analysis (11.3\%). TGA for SION-34 shows that guest and coordinated $\mathrm{H}_{2} \mathrm{O}$ molecules were removed in the temperature range of $30-280{ }^{\circ} \mathrm{C}$ with the total weight loss being $8.1 \%$. This weight loss observed in TGA is slightly lower than that calculated from elemental analysis (10.0\%). Decomposition of the framework starts at $295{ }^{\circ} \mathrm{C}$. Finally, the TGA profile of SION-35 shows that it is stable up to 210 ${ }^{\circ} \mathrm{C}$, and in the temperature range of $210-370{ }^{\circ} \mathrm{C}$, the coordinated $\mathrm{H}_{2} \mathrm{O}$ molecules are removed. The weight loss of $8.4 \%$ is in agreement with the calculated proportion $(9.1 \%)$ of the $\mathrm{H}_{2} \mathrm{O}$ molecules bound to $\mathrm{Zn}^{\mathrm{II}}$ from the elemental analysis.

Single-Crystal X-ray Diffraction Analysis. SION-31 crystallizes in the monoclinic space group $P 2_{1} / n$. The asymmetric unit (ASU) contains two symmetrically independent $\mathrm{Ni}^{\mathrm{II}}$ environments $(\mathrm{Ni} 1$ and $\mathrm{Ni} 2$ ) which are linked via the btc and adenine ligands. Two carboxylate groups of the btc ligand coordinate to the $\mathrm{Ni}^{\mathrm{II}}$ ions, while the third site is free of any metal binding. Since the bond distances between the $\mathrm{C}$ and O atoms, C16-O9 and C16-O10, are comparable (1.263(3) $\AA$ and $1.273(3) \AA$, respectively) and intermediate between the values of 1.35 and $1.21 \AA$ characteristic for, respectively, single and double $\mathrm{C}\left(\mathrm{sp}^{2}\right)-\mathrm{O}$ bonds, this site is a deprotonated carboxylate group; i.e., the btc ligand is $\mathrm{btc}^{3-}$. The charge is balanced with the adenine ligand in its anionic form $\mathrm{Ade}^{-51}$ Two Nil ions are part of a dimeric unit, which is bridged by two $\mathrm{Ade}^{-}$ligands via $\mathrm{N} 3$ and $\mathrm{N} 9$ and two $\mu_{2}-\mathrm{H}_{2} \mathrm{O}$ molecules to form a Ni-Ade secondary building unit (SBU) $\left[\mathrm{Ni}_{2}(\text { Ade })_{2}\left(\mathrm{H}_{2} \mathrm{O}\right)_{4}\left(\mu_{2}-\mathrm{H}_{2} \mathrm{O}\right)_{2}\right]^{2+}$ (Figure 2a). The octahedral coordination sphere of each $\mathrm{Nil}$ ion is filled by two terminal $\mathrm{H}_{2} \mathrm{O}$ ligands. The bond lengths of the $\mathrm{Ni}-\mathrm{O}_{\text {terminal }} \mathrm{H}_{2} \mathrm{O}$ bonds are 2.085(2) $\AA(\mathrm{Ni1}-\mathrm{O} 2), 2.020(2) \AA(\mathrm{Ni1}-\mathrm{O} 3)$, while the bond lengths of the $\mathrm{Ni}-\mathrm{O}_{\text {bridging } \mathrm{H}_{2} \mathrm{O}}$ are 2.1793(17) $\AA$ and 2.1234(16) A (Ni1-O1). These bond distances are consistent with those reported in the literature $\left(\left[\mathrm{Ni}_{2}\left(\mathrm{O}_{2} \mathrm{CFcCO}_{2}\right)_{2}\left(2,2^{\prime}\right.\right.\right.$ bpy $\left.)_{2}\left(\mu_{2}-\mathrm{OH}_{2}\right)_{2}\right] \cdot \mathrm{CH}_{3} \mathrm{OH} \cdot 2 \mathrm{H}_{2} \mathrm{O}:{ }^{52} \mathrm{Ni}-\mathrm{OH}_{2} \quad 2.107(9) /$ $2.138(3) \AA,\left[\mathrm{Ni}_{2}\left(\mathrm{H}_{2} \mathrm{O}\right)_{4} \mathrm{bdptz}\right](\mathrm{OTs})_{4} \cdot 2 \mathrm{CH}_{3} \mathrm{OH} \cdot \mathrm{H}_{2} \mathrm{O}:{ }^{53} \mathrm{Ni}-$ $\left.\mathrm{OH}_{2} 2.159(1) / 2.170(4) \AA\right)$, and are strikingly different from the bonds reported for bridging hydroxyl ligands (bis(1,5mesityl-3-nitroformazanato)-bis- $\mu$-hydroxonickel: ${ }^{54} \mathrm{Ni}-\mathrm{OH}$ $1.890(7) / 1.884(4) \AA ̊)$. The Ni2 ion also adopts an octahedral coordination geometry, with one chelating and one monodentate $\mathrm{btc}^{3-}$, one monodentate $\mathrm{Ade}^{-}$via N7, and two terminal $\mathrm{H}_{2} \mathrm{O}$ molecules as ligands (Figure $2 \mathrm{~b}$ ). SION-31 consists of two-dimensional sheets constructed by connecting the $\left[\mathrm{Ni}_{2}(\text { Ade })_{2}\left(\mathrm{H}_{2} \mathrm{O}\right)_{4}\left(\mu_{2}-\mathrm{H}_{2} \mathrm{O}\right)_{2}\right]^{2+}$ units augmented at two extremities with $\mathrm{Ni} 2$ atoms (Figure $2 \mathrm{a}$ ) via two deprotonated carboxylate groups of the $\mathrm{btc}^{3-}$ ligands (Figure $2 \mathrm{c}, \mathrm{d}$ ). The third carboxylate group of $\mathrm{btc}^{3-}$ forms $\mathrm{H}$-bonds with guest and coordinated $\mathrm{H}_{2} \mathrm{O}$ molecules. The noncoordinated $\mathrm{H}_{2} \mathrm{O}$ molecules (O1W, O2W, and $\mathrm{O} 3 \mathrm{~W}$ ) are hydrogen bonded with the $\mathrm{N} 1$ atom of $\mathrm{Ade}^{-}$and carboxylate O9, O11, and $\mathrm{O} 12$

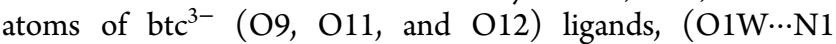

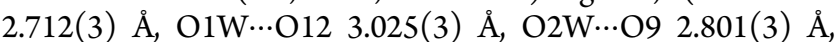
O3W…011 2.618(3) $\AA$ ), as well as with coordinated water molecules. The structure is close packed and exhibits no accessible voids.

Topological analysis with the program TOPOS reveals that the two-dimensional sheets in SION-31 form a hexagonal plane net (hcb), ${ }^{55}$ containing vertices of degree 3 centered on the lone $\mathrm{Ni} 2$ ions. The two dative bonds with $\mathrm{H}_{2} \mathrm{O}$ are disregarded as they do not contribute to the underlying network connectivity. The chelating $\mathrm{btc}^{3-}$ carboxylate group, the monodentate carboxylate of a different $\mathrm{btc}^{3-}$ ligand, and the $\mathrm{Ade}^{-}$N7 atom contribute as "edges" incident on this node. The remaining chemical species, including the Ni-Ade SBU, are considered as "2-connected" nodes in the topological description, and can therefore be reduced to a single edge in the hcb net (Figure S6).

SION-32 crystallizes in the tetragonal space group $\mathrm{P}_{2} / \mathrm{nmc}$. In the ASU, there is one $\mathrm{Ni}^{\mathrm{iI}}$ ion sitting on a special position with 0.5-occupancy, half deprotonated $\mathrm{ipa}^{2-}$ and one neutral 3 HAde ligand (protonated via N3, vide infra). The 3 Hade 

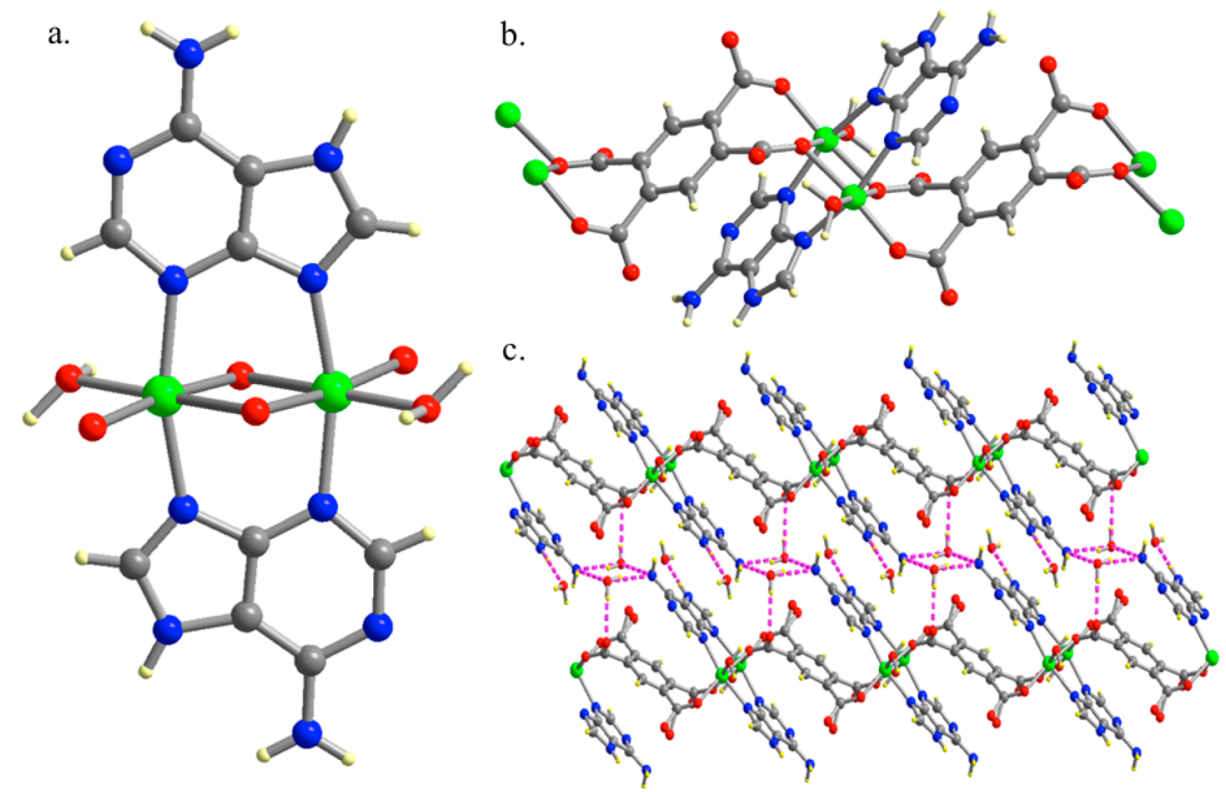

Figure 4. SION-33: (a) $\left[\mathrm{Ni}_{2}(7 \mathrm{HAde})_{2}\left(\mathrm{H}_{2} \mathrm{O}\right)_{2}\right]^{4+}$ "blade" dimer formed by the bridging coordination of $7 \mathrm{HAde} \mathrm{N} 9$ and N3 atoms. (b) The coordination of btec ${ }^{4-}$ and 7HAde around the octahedrally coordinated $\mathrm{Ni}^{\mathrm{II}}$ leads to the generation of one-dimensional chains of SION-33 along $b$ axis. (c) Packing scheme viewed along the $a$-axis showing the three-dimensional supramolecular structure; the array of hydrogen bonds between the framework $\mathrm{N}$ and $\mathrm{O}$ atoms and guest $\mathrm{H}_{2} \mathrm{O}$ molecules is represented as magenta dashed bonds. Color scheme: Ni, green; $\mathrm{C}$, gray; $\mathrm{O}$, red; $\mathrm{N}$, blue; and $\mathrm{H}$, yellow.
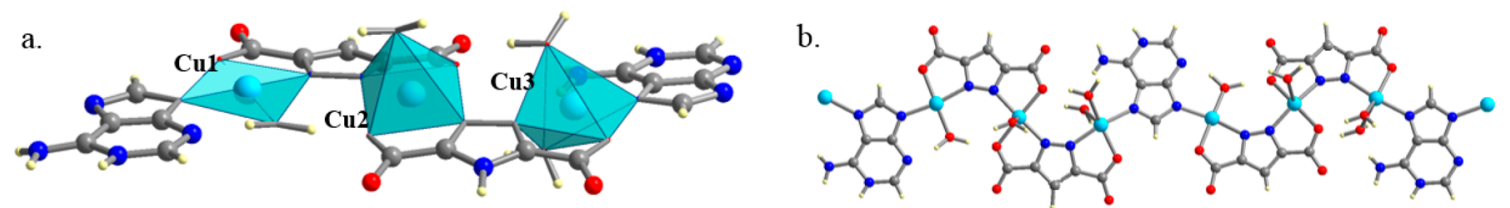

Figure 5. SION-34: (a) Coordination environment of Cu1 (square planar), Cu2 (tetragonal pyramid), and Cu3 (trigonal bipyramid) in SION-34. $1 \mathrm{HAde}$ acts as a bridging ligand coordinated to $\mathrm{Cu} 1$ and $\mathrm{Cu} 3$ through $\mathrm{N} 9$ and N7, respectively. The orientation of $1 \mathrm{HAde}$ and pzdc ${ }^{3-}$ around Cu1, $\mathrm{Cu} 2$, and $\mathrm{Cu} 3$ affords a one-dimensional chain. (b) Packing scheme showing the three-dimensional supramolecular structure. Color scheme: $\mathrm{Cu}$, light blue; $\mathrm{C}$, gray: $\mathrm{O}$, red; $\mathrm{N}$, blue; $\mathrm{H}$, yellow.

ligand is disordered as it assumes two equivalent orientations related to one another by a mirror plane. The coordination environment of $\mathrm{Ni}^{\mathrm{II}}$ is of distorted octahedral geometry, with four $\mathrm{O}$ atoms from two chelating $\mathrm{ipa}^{2-}$ ligands and two $\mathrm{N}$ atoms from two disordered 3HAde ligands completing its coordination geometry (Figure 3a). Each of the 3HAde and $\mathrm{ipa}^{2-}$ ligands behaves as a bridging linker between the $\mathrm{Ni}^{\mathrm{II}}$ ions, giving rise to a two-dimensional layered structure (Figure $3 b, c$ ). The packing of the two-dimensional layered structure of SION32 (Figure $3 c$ ) reveals that there is no accessible volume, as confirmed by PLATON. ${ }^{56,57}$

Topological analysis reveals that the two-dimensional layers in SION-32 form a square-lattice net (sql), which possesses single 4-connected nodes centered on the $\mathrm{Ni}^{\mathrm{iI}}$ atoms, while the $\mathrm{ipa}^{2-}$ and the 3HAde ligands represent the edges (Figure S7).

SION-33 crystallizes in the triclinic space group $P \overline{1}$. The ASU of SION-33 consists of one $\mathrm{Ni}^{\mathrm{II}}$ atom, one neutral 7 Hade ligand (protonated via N7, vide infra), half the btec ${ }^{4-}$ ligand, one coordinated and two guest $\mathrm{H}_{2} \mathrm{O}$ molecules. The 7HAde ligand binds to two chemically equivalent $\mathrm{Ni}^{\mathrm{II}}$ centers through N3 and N9. Two bridging 7HAde molecules coordinate on opposite sides of the $\mathrm{Ni}_{2}$ unit, forming a "blade" dimer, $\left[\mathrm{Ni}_{2}(7 \mathrm{HAde})_{2}\left(\mathrm{H}_{2} \mathrm{O}\right)_{2}\right]^{4+}$ (Figure 4a). Two symmetrically independent carboxylic groups of the btec ${ }^{4-}$ ligand bind to $\mathrm{Ni}^{\mathrm{II}}$ in two distinct ways: the first one coordinates to both $\mathrm{Ni}^{\mathrm{II}}$ atoms within the $\mathrm{Ni}_{2}$ unit in a monodentate mode through $\mathrm{O} 1$, whereas the neighboring carboxylate binds solely to one $\mathrm{Ni}^{\mathrm{II}}$ atom through $\mathrm{O} 4$ (Figure $4 \mathrm{~b}$ ). A terminal coordinated $\mathrm{H}_{2} \mathrm{O}$ molecule completes the octahedral coordination environment of $\mathrm{Ni}^{\mathrm{II}}$. The $\left[\mathrm{Ni}_{2}(7 \mathrm{HAde})_{2}\left(\mathrm{H}_{2} \mathrm{O}\right)_{2}\right]^{4+}$ dimers connected into one-dimensional chains extend along the $b$-axis (Figure $4 \mathrm{c}$ ). The O3W water molecule links these chains along the [001]

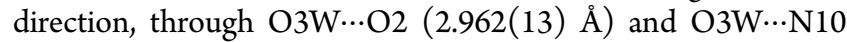
(2.930(13) $\AA)$ hydrogen bonds to one such chain, and through the $\mathrm{N} 10 \cdots \mathrm{O} 3 \mathrm{~W}(2.937(15) \AA) \mathrm{H}$-bond to the parallel one. Along [100], there are hydrogen bonds linking subsequent $\mathrm{Ni}_{2}$

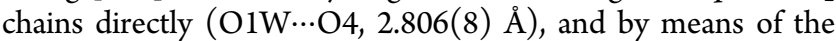

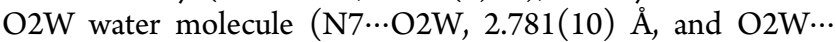
N1, 2.943(9) Å). Therefore, the array of hydrogen bonds combines 1D chains of $\left[\mathrm{Ni}_{2}(7 \mathrm{HAde})_{2}\left(\mathrm{H}_{2} \mathrm{O}\right)_{2}\right]^{4+}$ units into a three-dimensional supramolecular assembly. The packing and space filling representations of SION-33 show that it is not porous, which is further confirmed by PLATON. ${ }^{56}$

SION-34 crystallizes in the monoclinic space group $P 2_{1} / c$. The ASU consists of three symmetrically independent $\mathrm{Cu}^{\mathrm{II}}$ centers $(\mathrm{Cu} 1, \mathrm{Cu} 2$, and $\mathrm{Cu} 3)$, two fully deprotonated $\mathrm{pzdc}^{3-}$ ligands, one neutral 1HAde ligand (protonated via N1, vide infra), and four coordinated $\mathrm{H}_{2} \mathrm{O}$ molecules. $\mathrm{Cul}$ has a square planar geometry and is coordinated by one $\mathrm{N} 9$ atom from 1HAde, one pyrazolate $\mathrm{N} 2$ and one carboxylate $\mathrm{O} 1$ atom from 


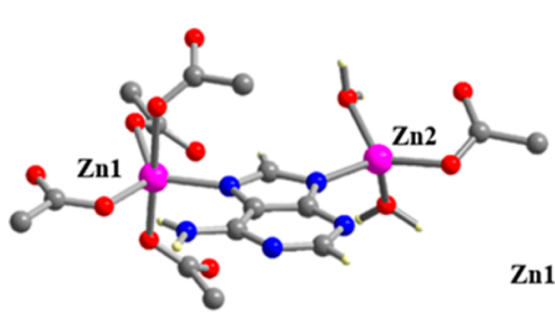

b. c.

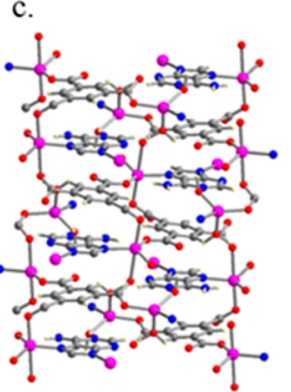

d.

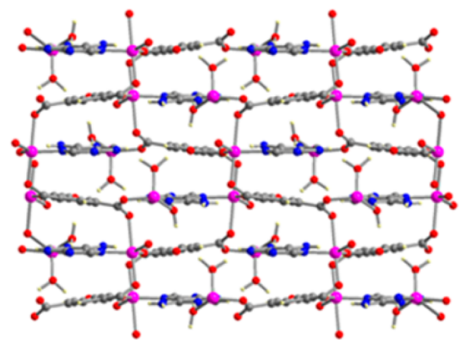

Figure 6. SION-35: (a) Coordination environments of $\mathrm{Zn} 1$ and $\mathrm{Zn} 2$; $\mathrm{Zn} 1$ holds a trigonal bipyramidal geometry and is coordinated via N7 of Ade ${ }^{-}$ and four $\mathrm{O}$ atoms from four adjacent btc ${ }^{3-}$ ligands; $\mathrm{Zn} 2$ is coordinated to $\mathrm{N} 9$ from $\mathrm{Ade}^{-}$, one $\mathrm{O}$ atom from btc ${ }^{3-}$ and two terminal $\mathrm{H}_{2} \mathrm{O}$ molecules, affording a distorted tetrahedral geometry. (b) Each btc ${ }^{3-}$ ligand is coordinated to five $\mathrm{Zn}^{\text {II }}$ ions. (c, d) The orientation of btc ${ }^{3-}$ and Ade ${ }^{-}$(in a zigzag fashion along $c$-axis and in a flat two-dimensional layer along $a$ - and $b$-axes) around $\mathrm{Zn} 1$ and $\mathrm{Zn} 2$ affords a three-dimensional compact structure. Color scheme: pink, $\mathrm{Zn}$; gray, $\mathrm{C}$; red, $\mathrm{O}$; blue, $\mathrm{N}$; and white, $\mathrm{H}$.

the same $\mathrm{pzdc}^{3-}$ ligand, while the fourth position is occupied by one $\mathrm{H}_{2} \mathrm{O}$, with the $\mathrm{Cu} 1-\mathrm{O} 1 \mathrm{~W}$ bond distance of $1.920(2) \AA$ (Figure $5 \mathrm{a}$ ). $\mathrm{Cu} 2$ is five coordinated with a tetragonal pyramidal geometry. The equatorial positions of $\mathrm{Cu} 2$ are occupied by two carboxylate $\mathrm{O}$ atoms (O3 and $\mathrm{O} 5$ ) and two $\mathrm{N}$ atoms (N4 and N6) from two adjacent pzdc ${ }^{3-}$ ligands. The axial position is occupied by the $\mathrm{O} 2 \mathrm{~W}$ atom from a $\mathrm{H}_{2} \mathrm{O}$ molecule with a bond distance of 2.323(2) A (Figure 5a). Cu3 is also coordinated by five donor atoms, giving rise to a trigonal bipyramid coordination geometry. The coordination environment of $\mathrm{Cu} 3$ is provided by $\mathrm{N} 12$ and $\mathrm{O} 7$ atoms from the $\mathrm{pzdc}^{3-}$ ligand, one $\mathrm{N} 7$ from 1HAde, and two $\mathrm{O}$ atoms, O3W and $\mathrm{O} 4 \mathrm{~W}$, from two distinct $\mathrm{H}_{2} \mathrm{O}$ molecules (bond distances of 2.281(2) and 1.969(2) $\AA$, respectively). As shown in the Figure $5 \mathrm{a}$, the connection of $\mathrm{Cu} 1-\mathrm{Cu} 2-\mathrm{Cu} 3$ via the $\mathrm{pzdc}^{3-}$ and 1HAde affords a one-dimensional chain extended along the crystallographic $[\overline{2} 01]$ direction. The adjacent one-dimensional chains are interlocked by the $\pi-\pi$ stacking interactions between the pyrimidine rings of 1 HAde (distance between two 1HAde ligands: 3.231(4) $\AA$ ) (Figure 5b), and by a system of hydrogen bonds to form a three-dimensional supramolecular array. Water molecules $\mathrm{O} 2 \mathrm{~W}, \mathrm{O} 3 \mathrm{~W}$, and $\mathrm{O} 4 \mathrm{~W}$, which protrude from the surface of a nearly planar $1 \mathrm{D}$ chain, serve as donors in a range of hydrogen bonds to the carboxylate $\mathrm{O}$ atoms of the $\mathrm{pzdc}^{3-}$ ligands situated above and below the chain: O2W…O 1,

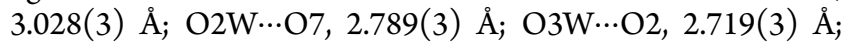

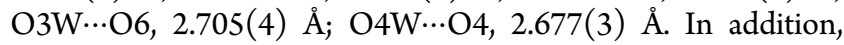
the pyrimidine $\mathrm{N} 1$ and amino N10 atoms of the 1HAde ligand provide the chain with linkage to the neighboring chains in the

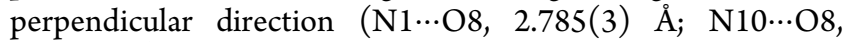
2.911(3) $\AA$ ). The dense packing of SION-34 indicates that it is nonporous.

SION-35 crystallizes in the monoclinic space group $P 2_{1} / c$. The ASU contains two independent $\mathrm{Zn}^{\mathrm{II}}$ ions ( $\mathrm{Zn} 1$ and $\mathrm{Zn} 2$ ), one $\mathrm{btc}^{3-}$, one bidentate $\mathrm{Ade}^{-}$, and two terminal $\mathrm{H}_{2} \mathrm{O}$ ligands bound to $\mathrm{Zn} 2$. $\mathrm{Zn} 1$ ions adopt a trigonal bipyramidal geometry, whereas $\mathrm{Zn} 2$ ions adopt a distorted tetrahedral coordination geometry. $\mathrm{Zn} 1$ and $\mathrm{Zn} 2$ are connected via the imidazolate $\mathrm{N}$ atoms, N7 and N9, respectively, of the Ade ${ }^{-}$ligand (Figure 6a). The completion of the coordination sphere of $\mathrm{Zn} 1$ is provided by four carboxylate $\mathrm{O}$ atoms from four adjacent $\mathrm{btc}^{3-}$ ligands with monodentate binding mode (Figure 6a). Two terminal $\mathrm{H}_{2} \mathrm{O}$ molecules are coordinated to $\mathrm{Zn} 2$, and the fourth position is occupied by a monodentate carboxylate $\mathrm{O}$ atom from the $\mathrm{btc}^{3-}$ ligand. These two specific coordination geometries of $\mathrm{Zn}^{\mathrm{II}}$ present in SION-35 are rarely observed in a single MOF. ${ }^{58}$
Each btc ${ }^{3-}$ ligand is bound to five $\mathrm{Zn}^{\mathrm{II}}$ atoms: four $\mathrm{Zn} 1$ and one $\mathrm{Zn} 2$ (Figure $6 \mathrm{~b}$ ). One carboxylate group of $\mathrm{btc}^{3-}$ is coordinated solely to $\mathrm{Zn} 1$ in a monodentate mode, whereas each of the other two groups is coordinated through a syn-anti coordination mode to two $\mathrm{Zn}^{\mathrm{II}}$ - to two $\mathrm{Zn} 1$ and to both $\mathrm{Zn} 1$ and $\mathrm{Zn} 2$ (Figure $6 \mathrm{~b}$ ). Both $\mathrm{btc}^{3-}$ and $\mathrm{Ade}^{-}$are packed in a zigzag fashion along the $c$-axis and as in a flat two-dimensional layer along the $b$ - and $a$-axes (Figure $6 \mathrm{c}, \mathrm{d}$ ). Through the coordination of the carboxylate $\mathrm{O}$ atoms of the $\mathrm{btc}^{3-}$ ligand

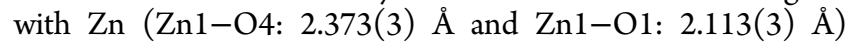
complemented by the system of hydrogen bonds, the $\mathrm{Zn}-$ Ade-btc layers are linked to each other propagating the structure into 3 dimensions. PLATON software reveals that there is no solvent accessible volume. ${ }^{56}$

To determine the topology of SION-35, small rings consisting of no more than 8 covalent or dative bonds were identified in the material. This includes an 8-membered ring consisting of both $\mathrm{Zn} 1$ and $\mathrm{Zn} 2$ ions coordinated to two carboxylate groups from separate btc $^{3-}$ ligands. This complex was reduced to a single node connected to 8 neighbors, including a 3-connected node representing the $b^{3-} c^{3-}$ ligand. The resulting 3,3,8-connected net has been reported in six previous structures as the " $3,38 \mathrm{~T} 25$ " topology (Figure S8). ${ }^{55}$

Investigation of the Protonation States of Adenine and Location of the Protonated N Atoms. As previously mentioned, adenine can afford different protonation states, and it is often very challenging to accurately observe the presence of $\mathrm{H}$ atoms by elemental analysis or SCXRD. The protonation states of the adenine ligand within a MOF structure can sometimes be assigned based on the charge balance of the structure, but the location of the protonated $\mathrm{N}$ atoms is not straightforward. XPS has been widely utilized as a reliable technique to assign protonation states of heterocyclic compounds. ${ }^{59}$ This technique is based on the general observation that individual chemical environments/functional groups often exhibit similar ranges of binding energy values where the bonding or electronegativity is similar. ${ }^{59}$ For example, the neutral 9HAde is expected to exhibit three photoemission $\mathrm{N}$ 1s peaks corresponding to three different nitrogen environments, i.e., the one of the N1, N3, N7 atoms, as all of them have the same $\mathrm{C}=\mathrm{N}-\mathrm{C}$ environment, and therefore should have very similar binding energies, which are different from the ones of $\mathrm{N} 9$ ( $\mathrm{C}-\mathrm{NH}-\mathrm{C}$ environment) and $\mathrm{N} 10$ (C- $\mathrm{NH}_{2}$ environment). This prediction, in fact, was experimentally demonstrated by Feyer et al. when they studied the XPS spectra of 9HAde in the gas phase. ${ }^{60}$ The $\mathrm{N} 1 \mathrm{~s}$ peaks 
a.

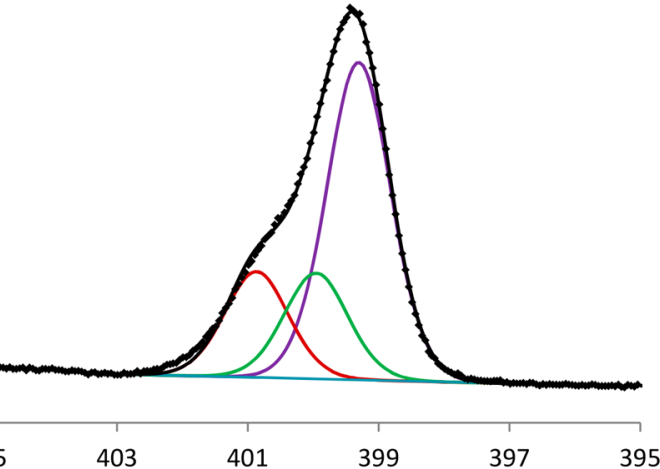

c.

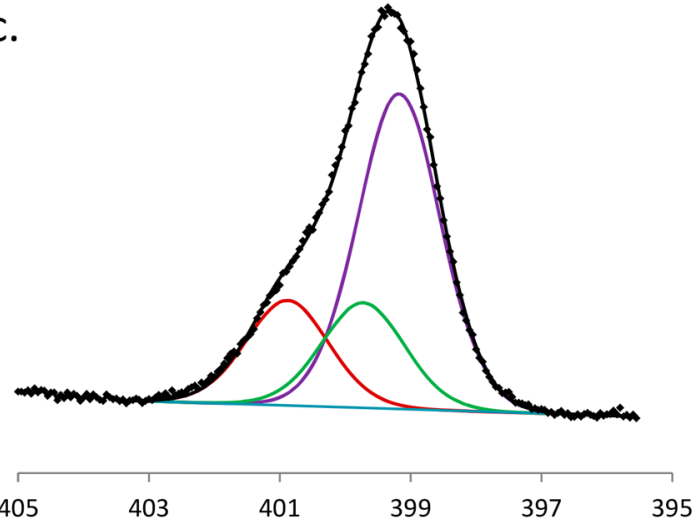

e.

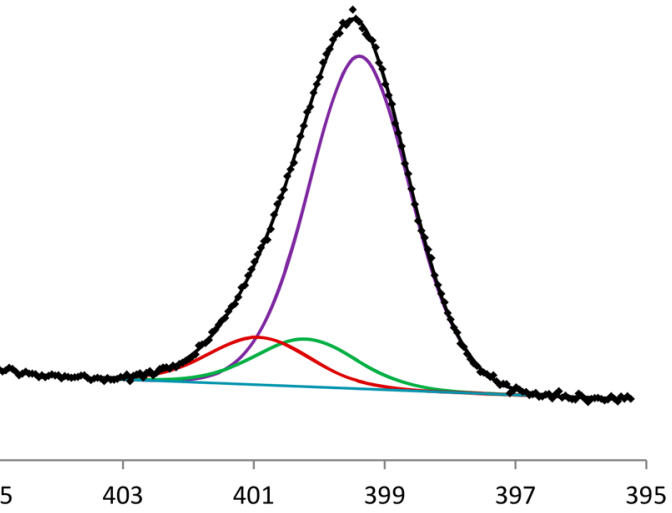

b.

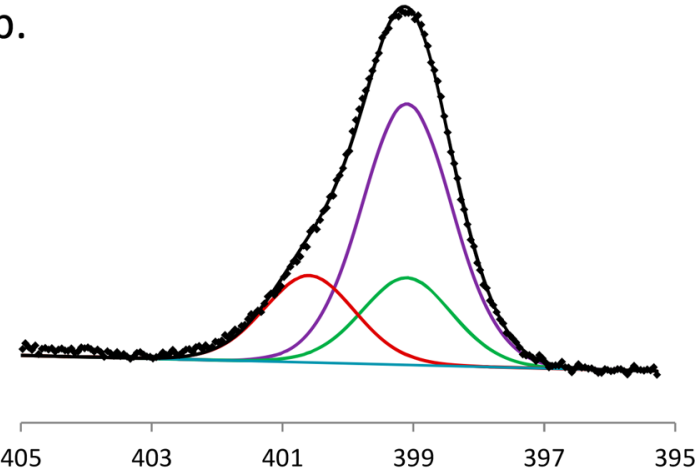

d.

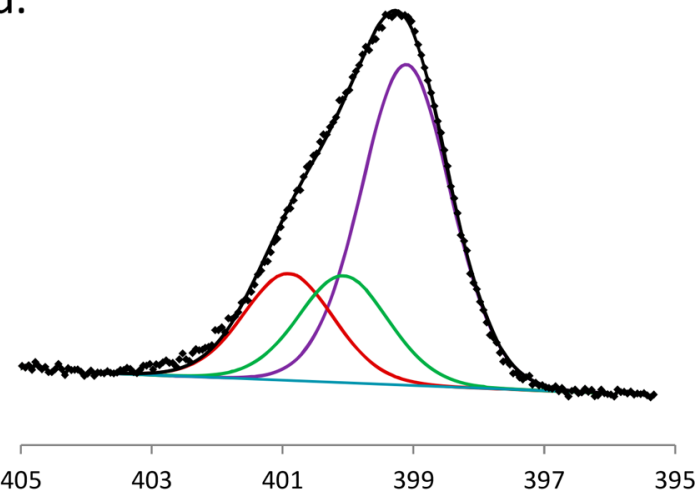

f.

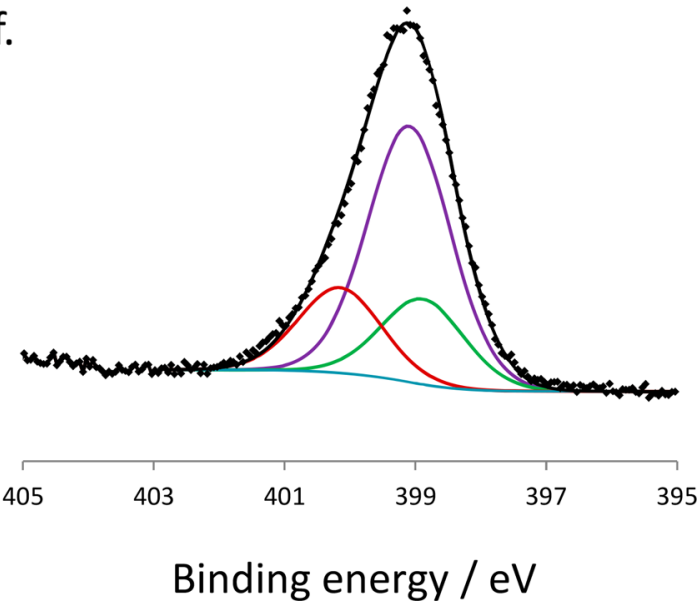

\section{Binding energy / eV}

Figure 7. N 1s photoelectron spectra of (a) neutral 9HAde, (b) SION-31, (c) SION-32, (d) SION-33, (e) SION-34, and (f) SION-35, in the solid state. The peaks were fitted with the three components A:B:C. Color scheme: Purple, component A (N1, N3, and N7); green, component B (N9); and blue, component $\mathrm{C}$ (N10) of adenine.

from each $\mathrm{N}$ atom of adenine in the gas phase appear in the range of 398-402 eV. The three peaks correspond to N1, N3, and N7, while the other two peaks represent N9 or N10. The difference in the binding energies of the $\mathrm{N}$ atoms becomes less pronounced when the XPS spectrum of adenine is measured in the condensed phase, i.e., in the solid state, probably due to the influences of intermolecular interactions. Furukawa et al. recorded the XPS spectrum from a thick film ( $\gg 1$ monolayer) of 9HAde on $\mathrm{Cu}(110)$; they fitted the N 1s XPS spectrum with two components with binding energies of $399.3 \mathrm{eV}$ (attributed to the imine nitrogen: N1, N3, and N7) and $400.6 \mathrm{eV}$ (attributed to both protonated $\mathrm{NH}$ or $\mathrm{NH}_{2}$ groups: $\mathrm{N} 9$ and
N10). ${ }^{61}$ However, the ratio of these two components was found to be 75:25, significantly different from the expected imine:amine ratio of 60:40. XPS measurement for 9HAde was repeated in the solid state, and we observed the same spectrum as reported by Furukawa et al. (Figure 7a), with a peak close to $399 \mathrm{eV}$ and a high energy shoulder, and adapted the three component model that has been successful for the gas phase. The three components represent $\mathrm{N}$ environments with different numbers of $\mathrm{N}-\mathrm{H}$ bonds. Component A represents imine nitrogen with no $\mathrm{N}-\mathrm{H}$ bonds: $\mathrm{N} 1, \mathrm{~N} 3$, and $\mathrm{N} 7$. Component $\mathrm{B}$ represents $\mathrm{N} 9$ which has one $\mathrm{N}-\mathrm{H}$ bond, and component $\mathrm{C}$ represents $\mathrm{N} 10$ in the $-\mathrm{NH}_{2}$ groups. Each 
component was modeled as a Guassian-Lorentzian peak. The area ratio of the components A:B:C was constrained according to the number of $\mathrm{N}$ atoms in 9 HAde they comprised, i.e., to the ratio of 3:1:1. The full width at half-maximum (FWHM) of all components was constrained to be equal in order to give a more physically realistic model. The neutral 9HAde compound was fitted with the model described, with the components $\mathrm{A}, \mathrm{B}$, and $C$ to be at binding energies of $398.49,399.14$, and 400.06 $\mathrm{eV}$, respectively (Figure $7 \mathrm{a}$ and Table 1 ). A difference in

Table 1. Binding Energies of Fitted Components for the $\mathrm{N}$ 1s Photoelectron Spectra ${ }^{c}$

\begin{tabular}{lccc} 
& \multicolumn{3}{c}{ binding energy $(\mathrm{eV})$ of component } \\
\cline { 2 - 4 } & $\mathrm{A}$ & $\mathrm{B}$ & $\mathrm{C}$ \\
9HAde & 398.49 & $399.14(+0.65)^{a}$ & $400.06(+1.57)^{a}$ \\
SION-31 & 399.10 & $399.10(+0.00)^{a}$ & $400.59(+1.49)^{a}$ \\
SION-32 & 399.17 & $399.49(+0.32)^{a}$ & $400.58(+1.41)^{a}$ \\
SION-33 & 399.12 & $400.08(+0.96)^{a}$ & $400.94(+1.82)^{a}$ \\
SION-34 & $399.04^{b}$ & $400.69(+1.65)^{a}$ & $400.69(+1.65)^{a}$ \\
SION-35 & 399.07 & $399.08(+0.01)^{a}$ & $400.32(+1.25)^{a}$
\end{tabular}

${ }^{a}$ Values in brackets are the differences of binding energy from component A. ${ }^{b}$ For SION-34, the component $\mathrm{A}$ includes the $\mathrm{N}$ atoms in the pzdc ${ }^{3-}$ ligand. ${ }^{c}$ Components $\mathrm{A}, \mathrm{B}$, and $\mathrm{C}$ were constrained to have the same FWHM, and the peak areas were constrained in the ratio $\mathrm{A}: \mathrm{B}: \mathrm{C}$ of $3: 1: 1$.

binding energies of $0.65 \mathrm{eV}$ was observed between components $\mathrm{A}$ and $\mathrm{B}$, and $1.57 \mathrm{eV}$ between $\mathrm{A}$ and $\mathrm{C}$. In the gas phase, the corresponding differences in binding energies were 1.3 and 2.3 $\mathrm{eV}{ }^{60}$ The model described, based on the chemical states expected in 9HAde, fits the experimental data well.

The XPS spectra of SION-31, SION-32, SION-33, SION34, and SION-35 were subsequently collected, with 9 Hade in the solid phase used to model the XPS spectra collected for each of these materials (Figure $7 b-f$ ). It should be noted that, since the pzdc ${ }^{3-}$ ligand in SION-34 contains different $\mathrm{N}$ atoms (two $\mathrm{pzdc}^{3-}$ ligands per $\mathrm{Ade}^{-}$ligand, therefore four nonprotonated $\mathrm{N}$ atoms per $\mathrm{Ade}^{-}$), these must also be included in the model for that material. ${ }^{62}$ The binding energy of each of the fitted components for all materials was allowed to vary, and the refined values are tabulated in Table 1 . It can be seen that, in two cases, in SION-31 and SION-35, the components A and B appear at very similar binding energies $(<0.1 \mathrm{eV}$ difference), whereas, in SION-32, SION-33, and SION-34, the separation was at least in the range of $0.3 \mathrm{eV}$. The appearance of these two components at the same binding energy was interpreted as the deprotonation of $\mathrm{N} 9$, bringing its binding energy down to coincide with the other deprotonated nitrogen environments N1, N3, and N7. On the other hand, separation between the components A and B suggests a loss of equivalence of chemical environments between one out of four following atoms: N1, N3, N7, or N9, and the remaining three. Therefore, the XPS data suggest that adenine is fully deprotonated and acts as an anionic ligand in SION-31 and SION-35, whereas, in SION32, SION-33, and SION-34, adenine is protonated, acting as a neutral ligand.

At this point, the structural questions for SION-31 and SION-35 are fully resolved: $\mathrm{Ade}^{-}$is a fully deprotonated ligand, which is in agreement with the formulas provided with SCXRD, assuring the charge balance. However, the information gained by the XPS that SION-32, SION-33, and SION-34 structures contain a neutral HAde ligand is inconclusive, since the protonation of adenine may take place on either N1 or N3 for SION-32 and SION-34, while the sites available in SION-33 are $\mathrm{N} 1$ or N7.

First, the difference-Fourier maps of SION-32, SION-33, and SION-34 were examined and probed for additional electron density maxima. Since these structures are solved using a synchrotron radiation diffraction data, the probability for peaks originating from $\mathrm{H}$ atoms appearing in the Fourier map was relatively high. Indeed, in the case of SION-33 and SION-34, the Fourier maps revealed the location of $\mathrm{H}$ atoms. In SION-33, two electron density maxima were identified in the proximity of $\mathrm{N} 7\left(0.55 \mathrm{e}^{-} / \AA^{3} 0.887 \AA\right.$ and $0.54 \mathrm{e}^{-} / \AA^{3} 1.104$ $\AA$ apart from this atom), and no maxima near N1. At the same time, the peak of $0.75 \mathrm{e}^{-} / \AA^{3}$ as far as $0.850 \AA$ from N1 was found in the difference-Fourier map of SION-34, while again no peaks were found in the vicinity of N3. In both cases, N1 and $\mathrm{N} 3$ act as acceptors of $\mathrm{H}$ bonds from neighboring guest water molecules, whose $\mathrm{H}$ atoms have also been localized in a similar way from the electron density map. However, the information obtained from the difference-Fourier map of SION-32 did not allow for an unequivocal assignment of $\mathrm{H}$ atom positions, which might be due to the disorder of adenine over two sites. Thus, an attentive consideration of adenine ligand geometry turned out to be necessary to determine the $\mathrm{H}$ atom position in SION-32.

In order to substantiate our observations of different protonation states present in the adenine-based SION-31, SION-32, SION-33, SION-34, and SION-35, and to resolve the problem of localization of the protonated N sites in SION32, SION-33, and SION-34, we systematically studied the bond angles of adenine in these structures. As a reference, the observation made by Singh $^{37}$ was used that, in 6-membered rings of purine derivatives, the $\mathrm{C}-\mathrm{N}-\mathrm{C}$ angles fall in the range of $125 \pm 3^{\circ}$ for the protonated $\mathrm{N}$ atoms, and of $116 \pm 3^{\circ}$ when the $\mathrm{H}$ atom is absent. For 5-membered rings, a similar relation states that, if N7 is protonated, then this 5-membered ring is more symmetrical, whereas, in the case of deprotonation of N7, the $\mathrm{C} 5-\mathrm{N} 7-\mathrm{C} 8$ angle increases by $3.8-5^{\circ} .{ }^{63}$ The respective bond angles for SION-31, SION-32, SION-33, SION-34, and SION-35 are listed in Table 2.

Table 2. Bond Angles (in Degrees) Calculated from the Crystal Structures of SION-31, SION-32, SION-33, SION34, and SION-35

$\begin{array}{lcccc} & \text { C6-N1-C2 } & \text { C2-N3-C4 } & \text { C5-N7-C8 } & \text { C4-N9-C8 } \\ \text { SION-31 } & 119.8(2) & 112.9(2)^{a} & 103.1(2)^{a} & 103.7(2)^{a} \\ \text { SION-32 } & 118.1(13) & 117.4(14) & 110.2^{a, b} & 106.1^{a, b} \\ \text { SION-33 } & 118.3(7) & 111.5(8)^{a} & 106.5(7) & 104.6(7)^{a} \\ \text { SION-34 } & 124.6(3) & 113.7(3) & 102.9(3)^{a} & 103.2(3)^{a} \\ \text { SION-35 } & 119.5(4) & 112.0(4) & 104.3(3)^{a} & 104.8(3)^{a} \\ { }^{a} \text { Metal coordinated to the N atom. }{ }^{b} \text { Angles modeled as part of an } \\ \text { idealized 5-membered ring. }\end{array}$

A survey of the Cambridge Structural Database (CSD version $5.38)^{64}$ was performed, and from the 61 adenine-based MOF crystal structures deposited with the CSD (Table S23), the bond angle values were extracted and are presented in the form of histograms (Figure 8). In many cases, the protonation of $\mathrm{N}$ sites of adenine is excluded, as they bind to the neighboring metal centers by means of coordination bonds. In all other cases, the $\mathrm{N}$ sites of adenine were classified as protonated or nonprotonated, and marked, respectively, as red and blue bars 

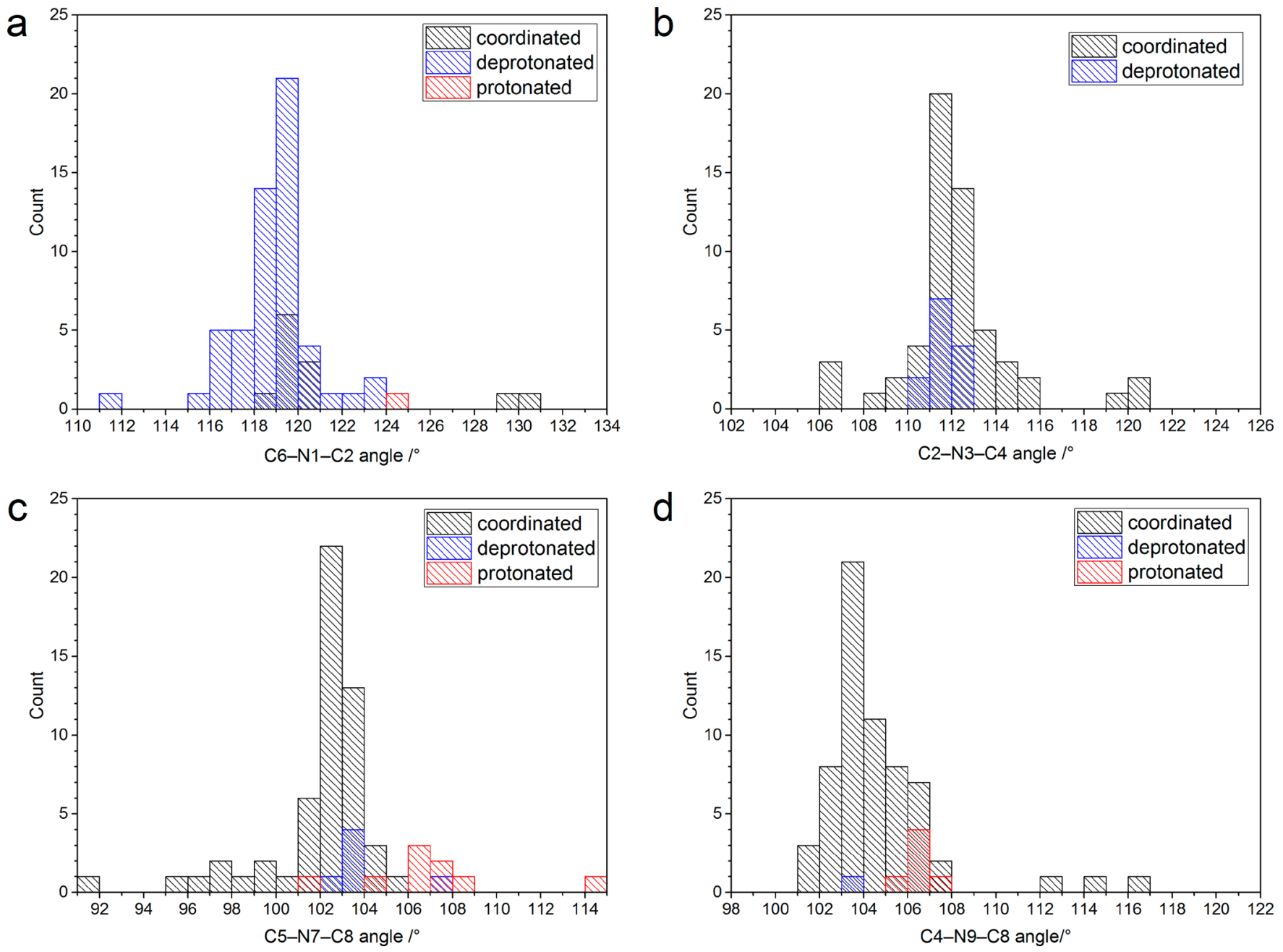

Figure 8. Distribution of the (a) $\mathrm{C} 6-\mathrm{N} 1-\mathrm{C} 2$, (b) $\mathrm{C} 2-\mathrm{N} 3-\mathrm{C} 4,(\mathrm{c}) \mathrm{C} 5-\mathrm{N} 7-\mathrm{C} 8$, and (d) C4-N9-C8 bond angle values in the adenine-based MOF structures found in the Cambridge Structural Database.

Table 3. Bond Angles and Relative Energies of DFT Optimized Structures of SION-32, SION-33, and SION-34 Simulated with All Probable Protonation Schemes ${ }^{a}$

\begin{tabular}{|c|c|c|c|c|}
\hline & $\mathrm{C} 6-\mathrm{N} 1-\mathrm{C} 2(\mathrm{deg})$ & $\mathrm{C} 2-\mathrm{N} 3-\mathrm{C} 4(\mathrm{deg})$ & C5-N7-C8 (deg) & $\Delta E(\mathrm{kcal} / \mathrm{mol})$ \\
\hline SION-32, N1-protonated & 123.50 & 113.97 & & \multirow{2}{*}{$15.44(\mathrm{~N} 3)$} \\
\hline SION-32, N3-protonated & 120.74 & 117.03 & & \\
\hline SION-33, N1-protonated & 123.21 & & 102.32 & \multirow{2}{*}{$12.90(\mathrm{~N} 7)$} \\
\hline SION-33, N7-protonated & 119.55 & & 107.84 & \\
\hline SION-34, N1-protonated & 124.45 & 114.46 & & \multirow{2}{*}{$13.29(\mathrm{~N} 1)$} \\
\hline SION-34, N3-protonated & 120.96 & 117.52 & & \\
\hline
\end{tabular}

in Figure 8. For the N1 atom, the span of the C6-N1-C2 angle was found to equal $119 \pm 3^{\circ}$ for the deprotonated sites, and the only structure with this site protonated, [Cd(1HAde)$\left.\left(\mathrm{SO}_{4}\right)\right],{ }^{65}$ was reported with the bond angle of $124.095^{\circ}$ (Figure 8a). Considering the bond angle values for SION-31, SION-32, SION-33, SION-34, and SION-35, we observe that the C6-N1-C2 angle has similar values for SION-31, SION32, SION-33, and SION-35, while such an angle in SION-34 is noticeably larger. Since the former group of angles fall in the range characteristic for deprotonated N1 sites, and the latter one is closer to the literature account on the $\mathrm{N} 1$ protonated adenine MOF, the data suggest that, in SION-31, SION-32, SION-33, and SION-35, the adenine ligand is N1 deproto- nated, while, in SION-34, the adenine ligand is protonated through N1 (Table 2). No published structures were found to be protonated at the $\mathrm{N} 3$, and all $\mathrm{C} 2-\mathrm{N} 3-\mathrm{C} 4$ angles fall in the range of $112 \pm 2^{\circ}$ (Figure $8 \mathrm{~b}$ ). Respective angles for SION-31, SION-33, SION-34, and SION-35 also fall in this range, which confirms the deprotonation of adenine on N3 (Table 2). The respective angle for SION-32, however, is visibly larger (Table 2). No literature reference is available, so we resorted to $a b$ initio calculations to confirm the location of protonation. For SION-32 and SION-34, i.e., the two MOFs where the protonation may take place on $\mathrm{N} 1$ or $\mathrm{N} 3$, we simulated and DFT optimized the respective $\mathrm{N} 1$ and $\mathrm{N} 3$ protonated structures, thus exploring all possibilities of protonation. The 
angles found in these DFT relaxed structures are listed in Table 3. Comparison between these data and the angles found experimentally (Table 2) confirms the $\mathrm{N} 3$ deprotonation of adenine in SION-34 (DFT: C2-N3-C4 of $114.46^{\circ}$ in the N3 deprotonated and $117.52^{\circ}$ in the $\mathrm{N} 3$ protonated structure; SCXRD: C2-N3-C4 of $\left.113.7(3)^{\circ}\right)$, and strongly suggests the protonation of SION-32 on N3 (DFT: C2-N3-C4 of $113.97^{\circ}$ in the $\mathrm{N} 3$ deprotonated and $117.03^{\circ}$ in the $\mathrm{N} 3$ protonated structure; SCXRD: C2-N3-C4 of $\left.117.7(13)^{\circ}\right)$. In addition, the calculations report an energy difference of $15.4 \mathrm{kcal}$ per mol of HAde residuals in favor of N3 protonation for SION-32. Meanwhile, in SION-34, the N1 protonation is favored by 13.3 $\mathrm{kcal} / \mathrm{mol}$, and its DFT-optimized angle distributions for $\mathrm{N} 1$ protonated $\left(124.45^{\circ}\right)$ and $\mathrm{N} 3$ deprotonated $\left(114.46^{\circ}\right)$ are closer to those reported for the structure in Table 2. Thus, based on insurmountable evidence, the adenine ligand in SION-34 is N1 protonated, while in SION-32 is clearly N3 protonated. We note that SION-32 was previously reported as an N1 protonated structure; ${ }^{57}$ however, in that study, the complicated disorder of adenine was not fully resolved (probably due to the low quality of data recorded at room temperature), thus not allowing for the precise geometrical analysis. In terms of the 5-membered ring present in the adenine ligand of the $\mathrm{CSD}$ reported MOFs, two maxima in the distribution of the $\mathrm{C} 5-\mathrm{N} 7-\mathrm{C} 8$ angle were observed: the first one at $103 \pm 1^{\circ}$ for the nonprotonated, and the second one at $107 \pm 2^{\circ}$ for the protonated N7 sites (Figure 8c). In the first case, an unexpectedly high value of this angle found at the nonprotonated $\mathrm{N} 7$ site, $107.964^{\circ}$, originated from $\left[\mathrm{Co}_{7}\left(\mathrm{H}_{2} \mathrm{O}\right)_{4^{-}}\right.$ (Ade $\left.)_{2}\left(\mu_{3}-\mathrm{OH}\right)_{6}(\mathrm{sip})_{2}\right]^{66}$ an example of a structure with the adenine ligand disordered over two sites. In the second case, the structures with extremely high $\left(114.52^{\circ},\left[\mathrm{Co}_{3}\left(\mu_{6}\right.\right.\right.$-TCPB $)$ $\left.\left.\left(\mu_{4}-\mathrm{H}_{2} \mathrm{TCPB}\right)(7 \mathrm{Hade})_{2}\right] \cdot \mathrm{H}_{2} \mathrm{O}^{36}\right)$ and low $\left(101.109^{\circ}\right.$, [Cd(7Hade $\left.)_{2} \mathrm{Cl}_{2}\right]^{67}$ ) $\mathrm{C} 5-\mathrm{N} 7-\mathrm{C} 8$ angle values turned out to have been reported with relatively high refinement indicators $\left(R_{1}=\right.$ $12.7 \%$ and $15.1 \%$, respectively). The $\mathrm{C} 5-\mathrm{N} 7-\mathrm{C} 8$ angle in SION-33 is very close to the second maximum (Table 2), and DFT relaxation of the N7 protonated structure yields C5-N7$\mathrm{C} 8$ and $\mathrm{C} 6-\mathrm{N} 1-\mathrm{C} 2$ angle values that agree well with the observed angles in the crystal structure (Table 3 ). The relative energy is $12.9 \mathrm{kcal} / \mathrm{mol}$ in favor of N7 vs N1 protonation. From this, we reason that the adenine ligand in SION-33 is protonated on N7. A shift toward higher values in the case of the N9 site protonation is also observed in the distribution of the $\mathrm{C} 4-\mathrm{N} 9-\mathrm{C} 8$ angles found in the reported structures (Figure 8d). The protonation states and coordination modes of adenine within the MOFs presented in this paper are shown schematically in Figure 9, while the trends of adenine $\mathrm{C}-\mathrm{N}-\mathrm{C}$ bond angles revealed by us within the literature adenine-based MOFs are summarized in Table 4. It should be noted that the statistical population considered in this survey was relatively small, which, on the one hand, indicates the need for use of supplementary methods (e.g., XPS and DFT) to unequivocally determine the protonation states of adenine in MOFs, but, on the other hand, highlights the demand for new adenine-based MOFs to be synthesized.

\section{CONCLUSIONS}

By varying the synthesis conditions, five adenine-based MOFs were isolated, and their crystal structures were solved using SCXRD. SION-31 and SION-32 were found to be twodimensional layered structures, SION-33 and SION-34 are based on one-dimensional chains (or three-dimensional
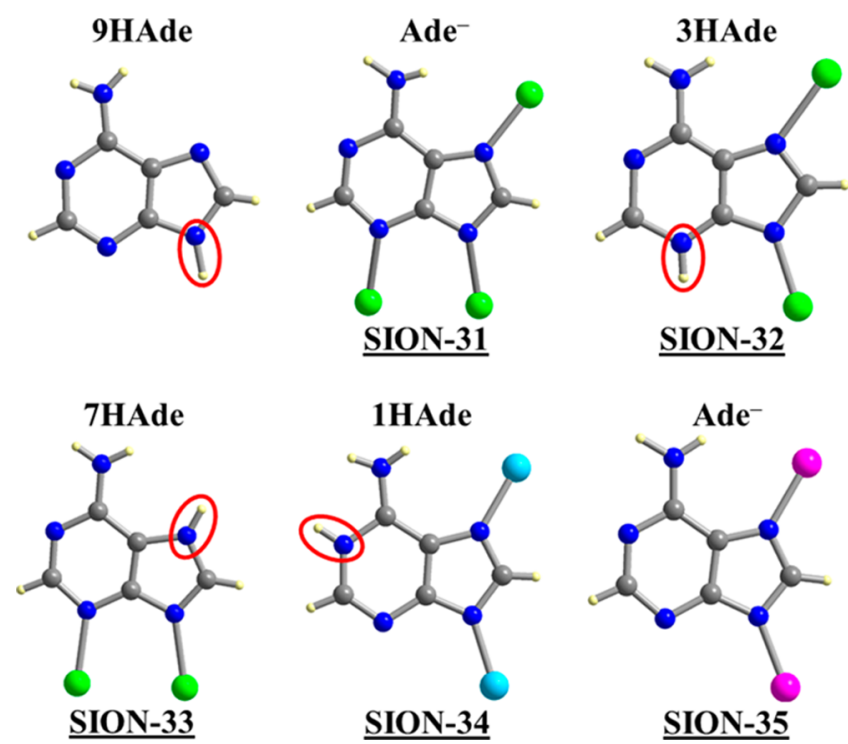

Figure 9. Protonation states and coordination modes of adenine within SION-31, SION-32, SION-33, SION-34, and SION-35.

Table 4. Regularities in the $\mathrm{C}-\mathrm{N}-\mathrm{C}$ Angle Values of Adenine Ligand within the Adenine-MOF Crystal Structures Reported in the Literature

\begin{tabular}{ccc} 
& N site nonprotonated & N site protonated \\
C2-N1-C6 & $119 \pm 4^{\circ}$ & $124 \pm 1^{\circ}$ \\
C2-N3-C4 & $112 \pm 2^{\circ}$ & NA \\
C5-N7-C8 & $103 \pm 1^{\circ}$ & $107 \pm 2^{\circ}$ \\
C4-N9-C8 & $103 \pm 1^{\circ}$ & $106 \pm 1^{\circ}$ \\
\hline
\end{tabular}

supramolecular assemblies), while SION-35 is a three-dimensional compact framework. A variety of metal $\left(\mathrm{Ni}^{\mathrm{II}}, \mathrm{Cu}^{\mathrm{II}}\right.$, and $\mathrm{Zn}^{\mathrm{II}}$ ) coordination geometries as well as different coordination binding modes of the ligands used $\left(\mathrm{H}_{3} \mathrm{btc}, \mathrm{H}_{2} \mathrm{ipa}, \mathrm{H}_{4} \mathrm{btec}\right.$, $\mathrm{H}_{3}$ pzdc, 9HAde) resulted in a range of structural topologies. ${ }^{68-70}$ The phase purity of each material was confirmed by PXRD and elemental analysis, and their thermal stability was checked by TGA.

Particular interest of our study has been drawn upon the coordination, protonation, and location of protonated $\mathrm{N}$ atoms of adenine present in all materials presented herein. XPS has successfully been used to determine the protonation of adenine in SION-31, SION-32, SION-33, SION-34, and SION-35. The $\mathrm{N}$ 1s photoelectron peaks were deconvoluted to three components, and the binding energy shifts between them showed significantly different values in the spectra of fully deprotonated SION-31 and SION-35, and those of protonated SION-32, SION-33, and SION-34. The protonation sites of adenine, derived from the difference-Fourier maps, were further confirmed by the study of $\mathrm{C}-\mathrm{N}-\mathrm{C}$ bond angles supported by the literature survey. As previously observed by Singh, the protonation of a given $\mathrm{N}$ site gives rise to an increase of the adjacent $\mathrm{C}-\mathrm{N}-\mathrm{C}$ bond angle, which is further supported by the DFT calculations. This strategy can be utilized to other MOF materials with very complex formulas where the balance of the charge of the formula is proven to be challenging. 


\section{ASSOCIATED CONTENT}

\section{S Supporting Information}

The Supporting Information is available free of charge on the ACS Publications website at DOI: 10.1021/acs.inorgchem.7b02761.

PXRD patterns, SEM images, TGA curves, crystallographic data, literature survey details, and topological analysis (PDF)

\section{Accession Codes}

CCDC 1574033 and 1576594-1576597 contain the supplementary crystallographic data for this paper. These data can be obtained free of charge via www.ccdc.cam.ac.uk/data_request/ cif, or by emailing data_request@ccdc.cam.ac.uk, or by contacting The Cambridge Crystallographic Data Centre, 12 Union Road, Cambridge CB2 1EZ, UK; fax: +44 1223336033.

\section{AUTHOR INFORMATION}

\section{Corresponding Author}

*E-mail: kyriakos.stylianou@epfl.ch.

\section{ORCID $\odot$}

Peter G. Boyd: 0000-0001-6541-0594

Robert G. Palgrave: 0000-0003-4522-2486

Berend Smit: 0000-0003-4653-8562

Matthew J. Rosseinsky: 0000-0002-1910-2483

Kyriakos C. Stylianou: 0000-0003-1670-0020

\section{Notes}

The authors declare no competing financial interest.

\section{ACKNOWLEDGMENTS}

K.C.S. and T.N.N. thank the Swiss National Science Foundation (SNF) for funding under the Ambizione Energy Grant no. PZENP2_166888. P.G.B. and B.S. were supported by the European Research Council (ERC) under the European Union Horizon 2020 research and innovation programme (grant agreement no. 666983, Magic). Access to the singlecrystal X-ray diffraction beamline BM01 at the European Synchrotron Radiation Facility (ESRF) is greatly acknowledged.

\section{REFERENCES}

(1) Férey, G. Hybrid porous solids: past, present, future. Chem. Soc. Rev. 2008, 37, 191-214.

(2) Yaghi, O. M.; O’Keeffe, M.; Ockwig, N. W.; Chae, H. K.; Eddaoudi, M.; Kim, J. Reticular synthesis and the design of new materials. Nature 2003, 423, 705-714.

(3) Farha, O. K.; Eryazici, I.; Jeong, N. C.; Hauser, B. G.; Wilmer, C. E.; Sarjeant, A. A.; Snurr, R. Q.; Nguyen, S. T.; Yazaydın, A. Ö.; Hupp, J. T. Metal-Organic Framework Materials with Ultrahigh Surface Areas: Is the Sky the Limit? J. Am. Chem. Soc. 2012, 134, 1501615021.

(4) Furukawa, H.; Ko, N.; Go, Y. B.; Aratani, N.; Choi, S. B.; Choi, E.; Yazaydin, A. Ö.; Snurr, R. Q.; O’Keeffe, M.; Kim, J.; Yaghi, O. M. Ultrahigh Porosity in Metal-Organic Frameworks. Science 2010, 329, 424-428.

(5) Furukawa, H.; Go, Y. B.; Ko, N.; Park, Y. K.; Uribe-Romo, F. J.; Kim, J.; O'Keeffe, M.; Yaghi, O. M. Isoreticular Expansion of MetalOrganic Frameworks with Triangular and Square Building Units and the Lowest Calculated Density for Porous Crystals. Inorg. Chem. 2011, 50, 9147-9152.

(6) Sumida, K.; Rogow, D. L.; Mason, J. A.; McDonald, T. M.; Bloch, E. D.; Herm, Z. R.; Bae, T.-H.; Long, J. R. Carbon Dioxide Capture in Metal-Organic Frameworks. Chem. Rev. 2012, 112, 724-781.
(7) Suh, M. P.; Park, H. J.; Prasad, T. K.; Lim, D.-W. Hydrogen Storage in Metal-Organic Frameworks. Chem. Rev. 2012, 112, 782835.

(8) He, Y.; Zhou, W.; Qian, G.; Chen, B. Methane storage in metalorganic frameworks. Chem. Soc. Rev. 2014, 43, 5657-5678.

(9) Li, S.-L.; Xu, Q. Metal-organic frameworks as platforms for clean energy. Energy Environ. Sci. 2013, 6, 1656-1683.

(10) Schoedel, A.; Ji, Z.; Yaghi, O. M. The role of metal-organic frameworks in a carbon-neutral energy cycle. Nat. Energy 2016, 1, 16034.

(11) Kurmoo, M. Magnetic metal-organic frameworks. Chem. Soc. Rev. 2009, 38, 1353-1379.

(12) Allendorf, M. D.; Bauer, C. A.; Bhakta, R. K.; Houk, R. J. T. Luminescent metal-organic frameworks. Chem. Soc. Rev. 2009, 38, $1330-1352$.

(13) Li, J.-R.; Kuppler, R. J.; Zhou, H.-C. Selective gas adsorption and separation in metal-organic frameworks. Chem. Soc. Rev. 2009, 38, $1477-1504$

(14) Lee, J.; Farha, O. K.; Roberts, J.; Scheidt, K. A.; Nguyen, S. T.; Hupp, J. T. Metal-organic framework materials as catalysts. Chem. Soc. Rev. 2009, 38, 1450-1459.

(15) Anderson, S. L.; Stylianou, K. C. Biologically derived metal organic frameworks. Coord. Chem. Rev. 2017, 349, 102-128.

(16) Beobide, G.; Castillo, O.; Cepeda, J.; Luque, A.; Pérez-Yáñez, S.; Román, P.; Thomas-Gipson, J. Metal-carboxylato-nucleobase systems: From supramolecular assemblies to $3 \mathrm{D}$ porous materials. Coord. Chem. Rev. 2013, 257, 2716-2736.

(17) Gładysiak, A.; Nguyen, T. N.; Navarro, J. A. R.; Rosseinsky, M. J.; Stylianou, K. C. A Recyclable Metal-Organic Framework as a Dual Detector and Adsorbent for Ammonia. Chem. - Eur. J. 2017, 23, 13602-13606.

(18) Choquesillo-Lazarte, D.; del Pilar Brandi-Blanco, M.; GarcíaSantos, I.; González-Pérez, J. M.; Castiñeiras, A.; Niclós-Gutiérrez, J. Interligand interactions involved in the molecular recognition between copper(II) complexes and adenine or related purines. Coord. Chem. Rev. 2008, 252, 1241-1256.

(19) Verma, S.; Mishra, A. K.; Kumar, J. The Many Facets of Adenine: Coordination, Crystal Patterns, and Catalysis. Acc. Chem. Res. 2010, 43, 79-91.

(20) Rojas-González, P. X.; Castiñeiras, A.; González-Pérez, J. M.; Choquesillo-Lazarte, D.; Niclós-Gutiérrez, J. Interligand Interactions Controlling the $\mu$-N7,N9-Metal Bonding of Adenine (AdeH) to the N-Benzyliminodiacetato(2-) Copper(II) Chelate and Promoting the N9 versus N3 Tautomeric Proton Transfer: Molecular and Crystal Structure of $\left[\mathrm{Cu}_{2}(\mathrm{NBzIDA})_{2}\left(\mathrm{H}_{2} \mathrm{O}\right)_{2}(\mu\right.$-N7,N9-Ade $\left.(\mathrm{N} 3) \mathrm{H})\right] \cdot 3 \mathrm{H}_{2} \mathrm{O}$. Inorg. Chem. 2002, 41, 6190-6192.

(21) Wang, F.; Tan, Y.-X.; Yang, H.; Zhang, H.-X.; Kang, Y.; Zhang, J. A new approach towards tetrahedral imidazolate frameworks for high and selective $\mathrm{CO}_{2}$ uptake. Chem. Commun. 2011, 47, 5828-5830.

(22) García-Terán, J. P.; Castillo, O.; Luque, A.; García-Couceiro, U.; Román, P.; Lezama, L. An unusual 3D coordination polymer based on bridging interactions of the nucleobase adenine. Inorg. Chem. 2004, 43, 4549-4551.

(23) Das, S.; Madhavaiah, C.; Verma, S.; Bharadwaj, P. K. A reusable zigzag copper(II) coordination polymer with bio-essential constituents as a facile DNA scission agent. Inorg. Chim. Acta 2005, 358, 32363240.

(24) Yang, E.-C.; Zhao, H.-K.; Ding, B.; Wang, X.-G.; Zhao, X.-J. The first $2 \mathrm{D}$ trinuclear $\mathrm{Cd}(\mathrm{II})$-complex with adenine nucleobase: Hydrothermal synthesis, crystal structure and fluorescent properties. New J. Chem. 2007, 31, 1887-1890.

(25) Yang, E.-C.; Zhao, H.-K.; Feng, Y.; Zhao, X.-J. A Tetranuclear $\mathrm{Cu}^{\mathrm{II}}$-Based 2D Aggregate with an Unprecedented Tetradentate $\mu_{4}$ N1,N3,N7,N9-Adeninate Nucleobase. Inorg. Chem. 2009, 48, 35113513.

(26) An, J. Y.; Geib, S. J.; Rosi, N. L. Cation-Triggered Drug Release from a Porous Zinc-Adeninate Metal-Organic Framework. J. Am. Chem. Soc. 2009, 131, 8376-8377. 
(27) An, J.; Geib, S. J.; Rosi, N. L. High and Selective $\mathrm{CO}_{2}$ Uptake in a Cobalt Adeninate Metal-Organic Framework Exhibiting Pyrimidineand Amino-Decorated Pores. J. Am. Chem. Soc. 2010, 132, 38-39.

(28) Stylianou, K. C.; Warren, J. E.; Chong, S. Y.; Rabone, J.; Bacsa, J.; Bradshaw, D.; Rosseinsky, M. J. $\mathrm{CO}_{2}$ selectivity of a $1 \mathrm{D}$ microporous adenine-based metal-organic framework synthesised in water. Chem. Commun. 2011, 47, 3389-3391.

(29) Pérez-Yáñez, S.; Beobide, G.; Castillo, O.; Cepeda, J.; Luque, A.; Aguayo, A. T.; Román, P. Open-Framework Copper Adeninate Compounds with Three-Dimensional Microchannels Tailored by Aliphatic Monocarboxylic Acids. Inorg. Chem. 2011, 50, 5330-5332.

(30) Wang, F.; Kang, Y. Unusual cadmium(II)-adenine paddlewheel units for the construction of a metal-organic framework with mog topology. Inorg. Chem. Commun. 2012, 20, 266-268.

(31) Pérez-Yáñez, S.; Beobide, G.; Castillo, O.; Cepeda, J.; Fröba, M.; Hoffmann, F.; Luque, A.; Román, P. Improving the performance of a poorly adsorbing porous material: template mediated addition of microporosity to a crystalline submicroporous MOF. Chem. Commun. 2012, 48, 907-909.

(32) An, J.; Farha, O. K.; Hupp, J. T.; Pohl, E.; Yeh, J. I.; Rosi, N. L. Metal-adeninate vertices for the construction of an exceptionally porous metal-organic framework. Nat. Commun. 2012, 3, 604.

(33) Li, T.; Rosi, N. L. Screening and evaluating aminated cationic functional moieties for potential $\mathrm{CO}_{2}$ capture applications using an anionic MOF scaffold. Chem. Commun. 2013, 49, 11385-11387.

(34) Li, T.; Chen, D.-L.; Sullivan, J. E.; Kozlowski, M. T.; Johnson, J. K.; Rosi, N. L. Systematic modulation and enhancement of $\mathrm{CO}_{2}: \mathrm{N}_{2}$ selectivity and water stability in an isoreticular series of bio-MOF-11 analogues. Chem. Sci. 2013, 4, 1746-1755.

(35) Li, T.; Kozlowski, M. T.; Doud, E. A.; Blakely, M. N.; Rosi, N. L. Stepwise Ligand Exchange for the Preparation of a Family of Mesoporous MOFs. J. Am. Chem. Soc. 2013, 135, 11688-11691.

(36) Burneo, I.; Stylianou, K. C.; Rodríguez-Hermida, S.; Juanhuix, J.; Fontrodona, X.; Imaz, I.; Maspoch, D. Two New Adenine-Based Co(II) Coordination Polymers: Synthesis, Crystal Structure, Coordination Modes, and Reversible Hydrochromic Behavior. Cryst. Growth Des. 2015, 15, 3182-3189.

(37) Singh, C. Location of hydrogen atoms in certain heterocyclic compounds. Acta Crystallogr. 1965, 19, 861-864.

(38) Dolomanov, O. V.; Bourhis, L. J.; Gildea, R. J.; Howard, J. A. K.; Puschmann, H. OLEX2: a complete structure solution, refinement and analysis program. J. Appl. Crystallogr. 2009, 42, 339-341.

(39) Sheldrick, G. SHELXT - Integrated space-group and crystalstructure determination. Acta Crystallogr., Sect. A: Found. Adv. 2015, $71,3-8$.

(40) Sheldrick, G. Crystal structure refinement with SHELXL. Acta Crystallogr., Sect. C: Struct. Chem. 2015, 71, 3-8.

(41) Hacene, M.; Anciaux-Sedrakian, A.; Rozanska, X.; Klahr, D.; Guignon, T.; Fleurat-Lessard, P. Accelerating VASP electronic structure calculations using graphic processing units. J. Comput. Chem. 2012, 33, 2581-2589.

(42) Hutchinson, M.; Widom, M. VASP on a GPU: Application to exact-exchange calculations of the stability of elemental boron. Comput. Phys. Commun. 2012, 183, 1422-1426.

(43) Kresse, G.; Furthmüller, J. Efficient iterative schemes for $a b$ initio total-energy calculations using a plane-wave basis set. Phys. Rev. B: Condens. Matter Mater. Phys. 1996, 54, 11169-11186.

(44) Kresse, G.; Furthmüller, J. Efficiency of ab-initio total energy calculations for metals and semiconductors using a plane-wave basis set. Comput. Mater. Sci. 1996, 6, 15-50.

(45) Kresse, G.; Hafner, J. Ab initio molecular-dynamics simulation of the liquid-metal-amorphous-semiconductor transition in germanium. Phys. Rev. B: Condens. Matter Mater. Phys. 1994, 49, 1425114269.

(46) Kresse, G.; Hafner, J. Ab initio molecular dynamics for liquid metals. Phys. Rev. B: Condens. Matter Mater. Phys. 1993, 47, 558-561.

(47) Grimme, S.; Antony, J.; Ehrlich, S.; Krieg, H. A consistent and accurate $a b$ initio parametrization of density functional dispersion correction (DFT-D) for the 94 elements H-Pu. J. Chem. Phys. 2010 $132,154104$.

(48) Perdew, J. P.; Burke, K.; Ernzerhof, M. Generalized Gradient Approximation Made Simple. Phys. Rev. Lett. 1997, 78, 1396-1396.

(49) Nazarian, D.; Ganesh, P.; Sholl, D. S. Benchmarking density functional theory predictions of framework structures and properties in a chemically diverse test set of metal-organic frameworks. J. Mater. Chem. A 2015, 3, 22432-22440.

(50) Kresse, G.; Joubert, D. From ultrasoft pseudopotentials to the projector augmented-wave method. Phys. Rev. B: Condens. Matter Mater. Phys. 1999, 59, 1758-1775.

(51) Note: In the section on single-crystal X-ray diffraction analysis, all conclusions on the protonation states of adenine are a posteriori made based on the XPS and geometrical dimension studies, described in detail in the following section. For further crystallographic data, see Tables S3S22.

(52) Meng, X. R.; Hou, H. W.; Li, G.; Ye, B. X.; Ge, T. Z.; Fan, Y. T.; Zhu, Y.; Sakiyama, H. Tetrametallic macrocyclic frameworks constructed from ferrocenedicarboxylato and 2,2'-bipyridine: synthesis, molecular structures and characteristics. J. Organomet. Chem. 2004, 689, 1218-1229.

(53) Barrios, A. M.; Lippard, S. J. Amide hydrolysis effected by a hydroxo-bridged dinickel(II) complex: Insights into the mechanism of urease. J. Am. Chem. Soc. 1999, 121, 11751-11757.

(54) Gilroy, J. B.; Patrick, B. O.; McDonald, R.; Hicks, R. G. Transition metal complexes of 3-cyano- and 3-nitroformazans. Inorg. Chem. 2008, 47, 1287-1294.

(55) Blatov, V. A.; Shevchenko, A. P.; Proserpio, D. M. Applied Topological Analysis of Crystal Structures with the Program Package ToposPro. Cryst. Growth Des. 2014, 14, 3576-3586.

(56) Spek, A. L. Single-crystal structure validation with the program PLATON. J. Appl. Crystallogr. 2003, 36, 7-13.

(57) Huang, H.-X.; Tian, X.-Z.; Song, Y.-M.; Liao, Z.-W.; Sun, G.-M.; Luo, M.-B.; Liu, S.-J.; Xu, W.-Y.; Luo, F. Three-Membered MetalNucleobase-Carboxylate System Showing Interesting 2D and 3D Architecture: Synthesis, Structure, Thermostability, and Magnetic Properties. Aust. J. Chem. 2012, 65, 320-325.

(58) Wu, S. T.; Ma, L. Q.; Long, L. S.; Zheng, L. S.; Lin, W. B. ThreeDimensional Metal-Organic Frameworks Based on Functionalized Tetracarboxylate Linkers: Synthesis, Strucures, and Gas Sorption. Inorg. Chem. 2009, 48, 2436-2442.

(59) Stevens, J. S.; Byard, S. J.; Muryn, C. A.; Schroeder, S. L. M. Identification of Protonation State by XPS, Solid-State NMR, and DFT: Characterization of the Nature of a New Theophylline Complex by Experimental and Computational Methods. J. Phys. Chem. B 2010, 114, 13961-13969.

(60) Feyer, V.; Plekan, O.; Prince, K. C.; Šutara, F.; Skála, T.; Cháb, V.; Matolín, V.; Stenuit, G.; Umari, P. Bonding at the organic/metal interface: Adenine to $\mathrm{Cu}(110)$. Phys. Rev. B: Condens. Matter Mater. Phys. 2009, 79, 155432.

(61) Furukawa, M.; Yamada, T.; Katano, S.; Kawai, M.; Ogasawara, H.; Nilsson, A. Geometrical characterization of adenine and guanine on $\mathrm{Cu}(110)$ by NEXAFS, XPS, and DFT calculation. Surf. Sci. 2007, $601,5433-5440$.

(62) Wenkin, M.; Touillaux, R.; Devillers, M. Bismuth derivatives of 2,3-dicarboxypyrazine and 3,5-dicarboxypyrazole as precursors for bismuth oxide based materials. New J. Chem. 1998, 22, 973-976.

(63) Hardgrove, G. L., Jnr; Einstein, J. R.; Hingerty, B. E.; Wei, C. H. Structure of adeninium dinitrate, $\mathrm{C}_{5} \mathrm{H}_{7} \mathrm{~N}_{5}{ }^{2+} .2 \mathrm{NO}_{3}{ }^{-}$. Acta Crystallogr., Sect. C: Cryst. Struct. Commun. 1983, 39, 88-90.

(64) Groom, C. R.; Bruno, I. J.; Lightfoot, M. P.; Ward, S. C. The Cambridge Structural Database. Acta Crystallogr., Sect. B: Struct. Sci., Cryst. Eng. Mater. 2016, 72, 171-179.

(65) Paul, A. K.; Sanyal, U.; Natarajan, S. Use of Polyazaheterocycles in the Assembly of New Cadmium Sulfate Frameworks: Synthesis, Structure, and Properties. Cryst. Growth Des. 2010, 10, 4161-4175.

(66) Yang, E.-C.; Liu, Z.-Y.; Zhang, L.; Yang, N.; Zhao, X.-J. Magnetism behaviours dominated by the interplay of magnetic 
anisotropy and exchange coupling in local $\mathrm{Co}_{7}{ }_{7}$ discs. Dalton Trans. 2016, 45, 8134-8141.

(67) Song, Y.; Yin, X.; Tu, B.; Pang, Q.; Li, H.; Ren, X.; Wang, B.; Li, Q. Metal-organic frameworks constructed from mixed infinite inorganic units and adenine. CrystEngComm 2014, 16, 3082-3085.

(68) Su, Z.; Fan, J.; Okamura, T.-a.; Sun, W.-Y.; Ueyama, N. LigandDirected and pH-Controlled Assembly of Chiral 3d-3d Heterometallic Metal-Organic Frameworks. Cryst. Growth Des. 2010, 10, 3515-3521.

(69) Bauer, S.; Serre, C.; Devic, T.; Horcajada, P.; Marrot, J.; Férey, G.; Stock, N. High-Throughput Assisted Rationalization of the Formation of Metal Organic Frameworks in the Iron(III) Aminoterephthalate Solvothermal System. Inorg. Chem. 2008, 47, 75687576.

(70) Volkringer, C.; Loiseau, T.; Guillou, N.; Férey, G.; Haouas, M.; Taulelle, F.; Elkaim, E.; Stock, N. High-Throughput Aided Synthesis of the Porous Metal-Organic Framework-Type Aluminum Pyromellitate, MIL-121, with Extra Carboxylic Acid Functionalization. Inorg. Chem. 2010, 49, 9852-9862. 